\title{
Monetary Policy and INEQUAlity Under Labor Market Frictions AND CAPITAL-Skill COMPLEMENTARITY
}

\author{
Juan J. Dolado, ${ }^{\dagger}$ Gergő Motyovszki ${ }^{\ddagger}$ and Evi Pappa ${ }^{\S}$
}

February 5, 2020

\begin{abstract}
We provide a new channel through which monetary policy has distributional consequences at business cycle frequencies. We show that an unexpected monetary easing increases labor income inequality between high and less-skilled workers. In particular, this effect is prominent in sectors intensive in less-skilled labor, that exhibit high degree of capital-skill complementarity (CSC) and are subject to matching inefficiencies. To rationalize these findings we build a New Keynesian DSGE model with asymmetric search and matching (SAM) frictions across the two types of workers and CSC in the production function. We show that CSC on its own introduces a dynamic demand amplification mechanism: the increase in high-skilled employment after a monetary expansion makes complementary capital more productive, encouraging a further rise in investment demand and creating a multiplier effect. SAM asymmetries magnify this channel.
\end{abstract}

Keywords: Monetary policy, Search and matching, Capital-skill complementarity, Inequality

JEL: E24, E25, E52, J64

${ }^{*}$ We are indebted to Benjamin Moll and three anonymous referees for many insightful comments which helped improve the paper substantially; to Arpad Abraham, Alessia Campolmi, Edouard Challe, Andresa Lagerborg, and Luis Rojas for useful inputs on earlier versions of this paper; and to Christian J.Meyer and Egon Tripodi for excellent research assistance. We also thank Jerome Adda, Juan Jimeno, Nicola Pavoni, Carlos Thomas, and participants in seminars at Bank of Spain, Bocconi University, CBS, Cemfi, Cunef, De Nederlandsche Bank, ADEMU-Banque de France Conference (EUI), EABCN Conference on The Effects of Unconventional Monetary Policy (UPF), and Bank of England for helpful remarks. We gratefully acknowledge financial support from the EUI (research grant IE-54) and the Spanish Ministerio de Economı y Competitividad (grant ECO2016-78652). The usual disclaimer applies.

${ }^{\dagger}$ Universidad Carlos III de Madrid, and CEPR, dolado@eco.uc3m.es

${ }^{\ddagger}$ European University Institute, gergo.motyovszki@eui.eu

${ }^{\S}$ Universidad Carlos III de Madrid, and CEPR, ppappa@eco.uc3m.es 


\section{Introduction}

During the last two decades growing inequality has become a key topic in the public debate, mainly pointing to long-term trends driven by technological change and globalization. However, following the financial crisis and the extreme measures central banks took to fight it, many questions have arisen about how monetary policy might affect inequality at business cycle frequencies. There are contrasting views on this issue. On the one hand, concerns have been expressed that the highly accommodative monetary policy stance in advanced economies, as with unconventional quantitative easing, favors richer households disproportionately, thereby contributing to more unequal income and wealth distributions. On the other hand, there are opinions supporting the opposite view, namely, that expansionary monetary policy reduces inequality because borrowers become better off than savers.

Of course central banks consider the economy as a whole when setting monetary policy. As pointed out by Bernanke (2015), distributional issues should not be the concern of monetary authorities but rather be addressed by democratically elected officials (e.g. through fiscal policy). A corollary of this view is that monetary policy can best contribute to social welfare by promoting aggregate economic stability, which can be beneficial from an inequality perspective. Notwithstanding this, it is increasingly acknowledged that the short-run effects of monetary policy on inequality could matter for its optimal design. Taking these effects into account might have welfare implications for various systematic monetary strategies, while inequality might also interact with the different channels of the monetary transmission mechanism. As a result, a recent strand of the literature has started to analyze how these issues are related.

The channels through which monetary policy affects inequality are complex. Interest rate changes can have different effects on savers and borrowers across the wealth distribution (the savings-redistribution channel). Asset prices (with various maturities) can react in different ways to changes in interest rates and/or inflation which in turn can influence inequality between the holders of these assets (the interest-sensitivity channel). Different household preferences and differing financial market access can also introduce heterogeneity in the effects of monetary policy (the household heterogeneity channel). More indirectly, the aggregate demand expansion engineered by monetary loosening can affect the outcomes of workers and capital owners differently, insofar as wages and profits change by different amounts (the income composition channel). Finally, the wages and employment of different types of workers can also exhibit heterogeneous responses, depending on unemployment risk, asymmetric wage rigidity, and labour market institutions (the earnings heterogeneity channel). ${ }^{1}$

The balance of all the above-mentioned forces is ambiguous and thus can only be determined using quantitative methods. Our main goal in the present paper is to focus only on one of the channels, namely labor earnings heterogeneity, leaving aside other sources of heterogeneity

\footnotetext{
${ }^{1}$ For more details on the different channels between monetary policy and inequality see Bell et al. (2012), Amaral (2017), Coibion et al. (2017) and Heathcote et al. (2010).
} 
(like, e.g. the wealth distribution). In particular, we uncover a new mechanism through which monetary policy affects labor-income inequality by investigating the interaction between capitalskill complementarity (CSC hereafter) in production, and labor market heterogeneity in searchand-matching (SAM) frictions of high vs. low-skilled workers. Skill-biased technological change has been traditionally considered as one of the main determinants of the growing trend in labor income inequality, as reflected by increasing gaps between the wages of high-skilled and lowskilled workers (skill premium) and their employment rates (relative employment). However, to the best of our knowledge, there has not been any analysis on the role played by the interaction of CSC and SAM frictions in explaining the effects of monetary policy on these gaps over the business cycle.

We start motivating our analysis by reporting the effects of monetary policy shocks on the skill premium and relative employment both for the aggregate US economy and six different sectors, using data from the Current Population Survey (CPS). Our main finding is that a monetary expansion (i.e., an unexpected reduction of 100 bp. in the annualized Federal Funds rate) increases on impact the skill premium and the relative employment of skilled vs. unskilled workers by 0.4 pp. and 0.35 pp., respectively, and that these effects are fairly long lasting. When the labor force is broken down into six sectors we report similar responses to an expansionary monetary shock in Manufacturing and in Wholesale and Retail Trade. Notably, these two sectors exhibit a large share of unskilled workers, underwent intense technological changes leading to massive restructuring and reallocation of activity during the 1990s (see, Foster et al. (2006)), and are characterized by similar degrees of CSC (see Blankenau and Cassou (2011)) and matching inefficiencies (see Şahin et al. (2014)). Hence, the characteristics exhibited by these two sectors seem to mimic the main ingredients of our model.

To rationalize these empirical findings, we build a model within the family of New Keynesian models with CSC embedded in the production function and SAM frictions á la DiamondMortensen-Pissarides (Blanchard and Galí, 2010) affecting high and low-skilled workers in an asymmetric fashion. CSC is captured through the elasticity of substitution between high-skilled labor and capital being below unity (making them complements), while it is above unity between low-skilled labor and capital (making them substitutes). High-skilled workers also face lower SAM-frictions in the form of lower separation rates, higher bargaining power and better matching efficiency. Krusell et al. (2000) introduced a CSC technology to study the effects of skill-biased technological change on the U.S. skill premium in the medium and long run, while Lindquist (2004) has shown that CSC is crucial to explain the behavior of the skill premium and labor income inequality at business cycle frequencies. As regards the asymmetric nature of SAM-frictions, Barnichon and Figura (2015) report that more educated workers have higher search efficiency despite the presumption that their labour market in thinner. Dolado et al. (2009) argue that a potential explanation of this result is that, while low-skilled workers can only undertake simple tasks, high-skilled workers can undertake both complex and simple tasks, being therefore more easily matched. Further, Wolcott (2018) reports that they also have lower 
separation rates.

Replicating the results in our empirical exercise, our theoretical model is able to predict that an unexpected cut in interest rates raises labor income inequality by increasing the relative labor share for high-skilled workers (who are already richer to begin with). This effect is mainly driven by an increase in the wage for the high skilled, who also fare better in terms of employment rates. The key assumption behind this result is the CSC production function since it introduces a dynamic demand amplification channel. The initial increase in high-skill employment induced by demand pressures after the monetary expansion, makes complementary capital more productive, encouraging a further rise in investment demand which creates further demand pressures (CSC channel) which are absent in a model with a standard Cobb-Douglas (CD) production function. This amplification is magnified further under asymmetric SAM frictions between skilled and unskilled workers (SAM-asymmetry channel). In effect, by considering this asymmetry, there is an additional source of initial imbalance in relative labor demand which interacts with higher demand pressures. With a sufficiently high degree of price rigidity, the introduction of CSC on its own is enough to generate a sizeable rise in the skill premium in a symmetric SAM environment. However, its interaction with asymmetric SAM frictions leads to a much larger rise in labor incomes inequality for a relatively low degree of price stickiness. This interaction is worth stressing, given the relevance of SAM asymmetries in the labor market.

It is important to highlight that these results are not specific to monetary policy shocks but also apply to any other favourable aggregate demand shock. Yet, we focus here on monetary shocks because they are likely to have quantitatively larger effects. This is due to their relatively more favourable impact on capital demand (important in the CSC channel), compared to government spending or discount factor shocks which, in contrast to monetary shocks, tend to crowd out investment. Offsetting aggregate demand pressures that lead to a rise of the relative demand for skilled labor might be desirable for monetary policy as long as income inequality is a policy concern. From this respect strict inflation targeting, which is successful in stabilizing the economy even in the presence of cost-push shocks (which present monetary policy with a trade-off between inflation and demand stabilization) is the most promising monetary strategy. Yet, we acknowledge that the simplicity of the model renders it limited for optimal policy experiments.

This paper is part of the recently growing literature on monetary policy and inequality. Most of the existing studies combine an incomplete market Aiyagari-type heterogeneous agent framework with New Keynesian nominal rigidities, resulting in what is now referred to as HANK models (see, for example Kaplan et al. (2018); Ravn and Sterk (2018); Luetticke (2017)). Gornemann et al. (2012) use this framework, augmented by SAM frictions, to make unemployment risk endogenous to monetary policy. They show that, unlike in our model, contractionary monetary shocks are the ones that increase income inequality - via a rise in precautionary savings by poorer households which leads to a higher value of the assets held by the wealthy rich and therefore have larger welfare costs than thought before. Yet, Gornemann et al. (2016) and 
other existing studies do not account for either CSC or asymmetric SAM frictions across skills. Instead, we abstract from the role of uninsured idiosyncratic risk and the wealth distribution, and rather focus on the earnings heterogeneity channel. Thereby our paper provides an alternative theoretical insight into a new transmission mechanism of monetary policy to labor income inequality which, to the best of our knowledge, is novel in this area of research.

Moreover, to the best of our knowledge, this is the first paper to bring direct evidence on the effects of monetary policy shocks on the skill premium and the relative employment of high vs. low-skilled workers, both at the aggregate level and at the industry level. Contrary to our findings, Coibion et al. (2017) (using local projections) find that contractionary monetary policy shocks (identified as in Romer and Romer (1998)) systematically increase inequality as rising unemployment falls disproportionately on low-income workers. In the Online Appendix we show that the differences in conclusions with Coibion et al. (2017) are due to the different measures of inequality used.

The rest of the paper is organized as follows. In Section 2 we motivate our further analysis by estimating the dynamic effects of monetary policy shocks on the skill premium and the relative employment in structural VAR (SVAR) models. Section 3 lays out the theoretical model, while Section 4 discusses our calibration strategy. Results and sensitivity analysis are presented and discussed in Section 5. A final section provides concluding remarks. An Appendix gathers detailed information on the construction of the labor market variables and on additional estimation and simulation results. An Online Appendix provides the detailed structure of the model and its calibration. ${ }^{2}$

\section{Monetary Policy and Labor Income Inequality: SVAR evi- dence}

To motivate our research question, we start by identifying the impact of an expansionary monetary policy shock on the skill premium and the relative employment rates of high and low-skilled workers (employment-rate ratio) in a SVAR model. We construct time series of both gaps using the NBER extracts of the Current Population Survey (CPS) Merged Outgoing Rotation Groups, including in the sample only individuals in working age 15-64 and excluding part-time workers, self-employed and military employees. CPS provides monthly information from 1979:1 until 2016:6 on the participants' employment status, level of education, weekly earnings, and weekly hours of work. We classify workers as high-skilled and less-skilled according to whether they have experienced some college or not. Employment is defined as number of monthly hours of work per employee times the number of salaried workers in each skill category. We obtain hourly wages for both types of workers by computing the ratio of weekly wages and the corresponding

\footnotetext{
${ }^{2}$ The Online Appendix is available at: https://sites.google.com/site/evipappapersonalhomepage/home/research/workingpapers
} 
number of weekly hours worked in each group.

In spite of being seasonally adjusted, the derived wage and employment series from the CPS micro data turn out to be too volatile at the monthly frequency. In line with the optimal choice of lag length in the VAR (5 lags), we use a backward 5-month moving average to smooth the data. Notice that, since we want to use these series in a VAR, each variable (time series) has to be modeled as a function of past values of the series, which justifies the choice of a backward moving average instead of a centered one involving future values. ${ }^{3}$ These smoothed wage series are then used to compute the skill premium, i.e. the ratio between the weighted average of hourly wages of the high-skilled and low-skilled workers. Consistent with the evidence of Castro and Coen-Pirani (2008), the unconditional correlation between the constructed skill premium and the unemployment rate is -0.07 in the raw data, indicating that the skill premium is slightly pro-cyclical in our sample, while the one between the relative employment ratio and the unemployment rate equals 0.21 , pointing to counter-cyclicality of high-skilled employment.

As Ramey (2016) acknowledges, it is very hard to identify meaningful monetary policy shocks on samples that include recent decades. Ramey (2016) also shows that, irrespective of the sample period considered, the method used to identify shocks in monetary policy might create several puzzles, such as the price puzzle, i.e. an increase in inflation after a monetary contraction, or the fact that contractionary monetary policy shocks appear to be expansionary in the post 1980 period. As a result, we proceed sequentially meaning that, prior to looking at the effects of monetary policy on our two variables of interest, we search for specifications for the aggregate US economy (abstracting from the labor market variables) that produce meaningful responses of the remaining variables in the SVAR to a monetary policy shock. To recover meaningful monetary policy shocks in the data we use the IV-SVAR approach advocated by Mertens and Ravn (2012) and Stock and Watson (2018). The central idea of this estimation procedure is the use of external instruments for the structural shocks of interest in a VAR setting. Following Mertens and Ravn (2012), we use the extended time series of the Romer and Romer (2004) narrative/Greenbook shocks constructed by Wieland (2016) till 2007 as a noisy measure of the true shocks in the Federal funds rate.

We examine monthly data covering the sample period January 1980-December 2007. The sample stops in 2007 both to exclude the financial crisis and for the practical reason that the Romer and Romer (2004) narrative series are not available after that date. ${ }^{4}$ Our SVAR consists of seven

\footnotetext{
${ }^{3}$ Admittedly, smoothing the series is not innocuous. In the Online Appendix, we present the original IRFs of the VAR with the original labor market series. The VAR with the raw series exhibits an initial spike at 2, yet the skill premium increases significantly for about 32 months also in this specification. Smoothing, thus, matters for the quantitative results (the impact effect is smaller when using the smoothed series but the dynamic responses last longer than with the raw data).

${ }^{4}$ Miranda-Agrippino (2016) has extended those series until 2012. In the Online Appendix we show that our results are robust when the sample is extended up to that year. Results are also robust if we use the extended narrative series of Romer and Romer (2004) constructed by Coibion et al. (2017). The series of Wieland (2016) are one year shorter but, perhaps not surprisingly, results are very similar since the correlation between the two
} 

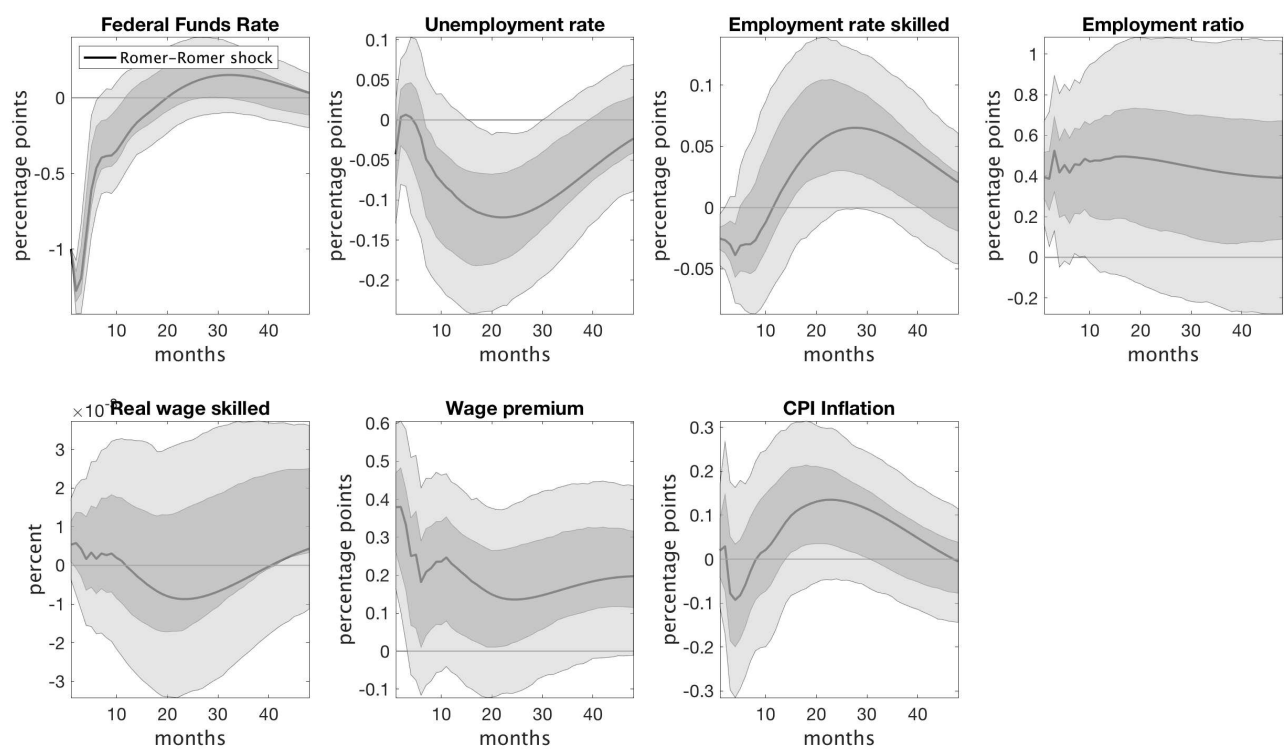

Figure 1: IRFs to a one percentage point unexpected reduction in the FF interest rate

variables: the unemployment rate, the log of real wages for skilled workers, the skill premium, the skilled employment rate, the relative employment rate, the consumer price index inflation, and the federal funds rate (FFR). Notice that by including the individual variables for skilled workers in addition to the skill and employment gaps, we are also able to retrieve the responses of the variables corresponding to unskilled workers variables. Data for both the unemployment rate and the CPI for all urban consumers are drawn from the Bureau of Labor Statistics; data for the effective FFR are produced by the Board of Governors of the Federal Reserve System. All variables except for the FFR are seasonally adjusted. Using different information criteria (AIC, HQ and BIC), we include five lags of each variable in the VAR.

Figure 1 displays point estimates and 68 (darker bands) and 95 (lighter bands) percent confidence intervals for the impulse function responses (IRFs) of the baseline SVAR model to the identified monetary policy shock. ${ }^{5}$ As far as the aggregate macroeconomic variables are concerned, the shock has expansionary effects after some delay. Following the unexpected interest-rate cut, unemployment falls persistently. The response of the CPI inflation is negative but mostly non significant, alleviating concerns about the price puzzle in our chosen specification (See Ramey (2016)). Regarding the labor market variables, the skill premium and the employment ratio increase significantly on impact and they remain persistently above trend (at 68 percent confidence level), while the real wage and the employment rate of the high skilled also increase though

series for the rest of the observations is 0.99. Finally, we also consider a Cholesky ordering for the whole sample period 1980-2016, obtaining that the skill premium and relative employment for skilled workers also increase in this experiment. Yet, these results need to be taken with some caution since the zero-lower bound (ZLB) was binding in that sample and the monetary policy conduct before and after 2007 was subject to regime shifts.

${ }^{5}$ The Romer and Romer narrative series have an F-statistic of 42.8 in the first-stage regression, rejecting the null hypothesis of a weak instrument at the 5 percent significance level. 
the former is only significant on impact. ${ }^{6}$ Overall, the reported IRFs suggest that inequality between high and low-skilled workers (in terms of wages and employment rates) is positively related to an unexpected cut in interest rates. At the peaks of the IRFs, the employment rate ratio increases by about 0.35 percentage points while the skill premium raises by around 0.4 percentage points.

In the Online Appendix we show that a monetary expansion robustly increases the wage premium and relative employment when we control for composition effects, and when we do not smooth the wage series. Moreover, given the discrepancy between our results and Coibion et al. (2017)'s, we repeat our exercise adopting the local projections methodology employed by Coibion et al. (2017) to identify the effects of a monetary policy contraction on inequality. We show that a monetary contraction decreases significantly the real wage of skilled and the wage premium when we use direct local projections to estimate the responses of those variables to such a shock. The differences in conclusions with Coibion et al. (2017) is due to the different series considered to measure inequality. While our focus is on the skill premium and relative employment, drawing data from the NBER extracts of the Current Population Survey (CPS), Coibion et al. (2017) construct measures of inequality using the Consumer Expenditure Survey (CEX) and report results for inequality in labor income, total income, consumption and total expenditures. Furthermore, Coibion et al. (2017) acknowledge that their results are sensitive regarding earnings inequality. Indeed, for some of their empirical specifications, earnings inequality increases after a monetary expansion in accordance to the evidence presented here.

Next, in the different panels of Figure 9 in Appendix B we display the IRFs of the skill premium and relative employment in six sectors of the US economy: (1) Manufacturing, (2) Education and Health Services, (3) Agriculture, Mining and Transportation, (4) Wholesale and Retail Trade, (5) Professional Services, (6) Financial and Informational Services in that order. ${ }^{7}$ The IRFs of the relative employment and the skill premium in the Manufacturing (Sector 1) and the Wholesale and Retail sector (sector 4) are the ones that mimic qualitatively the IRFs reported earlier for the aggregate data. For the remaining four sectors results are mixed. Hence, the evidence from the sectoral data points to the importance of CSC for the underlying mechanism behind the responses of the wage premium and relative employment to a monetary expansion.

In what follows we highlight the role of CSC and asymmetric SAM frictions in generating the pattern of responses observed for the labor market of skilled and less skilled workers both in Wholesale and Retail Trade and Manufacturing. Notice that these two sectors share several common features: (a) they represent industries which have a relatively high share of less-skill

\footnotetext{
${ }^{6}$ The response of the skilled real wage is sensitive to the specification used. For most of the alternative specifications considered in the Online Appendix, the real wage for skilled increases significantly after the monetary expansion.

${ }^{7}$ Due to data limitations we were unable to dis-aggregate these sectors further. For ease of exposition we only present IRFs of the labor market variables, since the responses of the aggregate variables are similar to those displayed in Figure 1.
} 
workforce, as in the aggregate ; (b) according to Blankenau and Cassou (2011), who classify industries in a similar way, the elasticity of substitution between low and high-skilled labor inputs and the rate of skill-biased technological progress is similar in these two sectors; (c) both underwent a massive restructuring and reallocation of activity in the 1990s, in parallel with intense technological advances (see, Foster et al. (2006)); (d) according to Şahin et al. (2014), they are characterized by similar degree of matching efficiencies in the labor market (using hires from the CPS, the estimates for industry-specific match efficiencies before 2007 are 0.38 in Wholesale and Retail Trade, and 0.42 in Manufacturing). Finally, using data from the American Community Survey, Rose (2017) confirms anecdotal evidence suggesting that a large fraction of job holders in the retail sector are overqualified despite the low share of the high skilled. For example, 22 percent of male and 18 percent of female workers hold a BA and work as retail salespersons, 6 percent of male laborers and freight, stock and material movers and 20 percent of female customer service have completed a BA degree, where all the aforementioned jobs have low or no-skill requirements. In sum, these two sectors exhibit characteristics which mimic better than the remaining ones those features which are relevant for our proposed mechanism.

In view of these empirical findings, a theoretical model is presented in the next section to rationalize them, as well as to provide new insights about the interaction between monetary policy shocks and labor income inequality.

\section{Model}

Our model belongs to the family of New Keynesian DSGE models with SAM frictions in the labor market (Blanchard and Galí, 2010). The New Keynesian feature of nominal rigidities ensures that monetary policy has real effects on the macro-economy, while SAM frictions allow us to model unemployment. Heterogeneity in the population manifests itself along two dimensions: there are three different households types (high and low-skilled workers, and capital investor entrepreneurs, with no transitions among these three groups), as well as three different labor market status (employed, unemployed and inactive) endogenously governed by SAM frictions. Skill types differ in their labor market frictions ( "asymmetric" SAM) (See, Brückner and Pappa (2012), and Pappa et al. (2015)) and also in their role in production: high-skilled workers have a lower elasticity of substitution with capital than low-skilled workers do $(C S C)$. Different households can trade with each other in a full set of state-contingent Arrow securities. This complete financial market setup provides perfect insurance against endogenous idiosyncratic unemployment risk within a given skill group, as well as against the asymmetric effects of aggregate shocks across different types, leading to constant consumption inequality. This assumption allows us to focus on cyclical fluctuations in labor income inequality. ${ }^{8}$ Finally, we have an endogenous

\footnotetext{
${ }^{8}$ In the working paper version of this paper, Dolado et al. (2018), we consider imperfect risk sharing (through a single risk free bond) across skill types against the asymmetric effects of aggregate shocks (while maintaining full risk sharing within a particular skill type against idiosyncratic unemployment risk). This leads to fluctuating
} 
participation choice as in Ravn (2006), Brückner and Pappa (2012), Campolmi and Gnocchi (2016) and Christiano et al. (2016).

Perfectly competitive intermediate good firms produce a homogeneous output by renting capital from entrepreneurs and the two types of labor from workers. Hiring and firing are subject to SAM frictions and wages are set by Nash bargaining. Intermediate output is then differentiated by monopolistically competitive retail firms who face Calvo-type nominal rigidities in the price of the final good. Final output is used for consumption, investment and (wasteful) government spending. Fiscal policy finances exogenous expenditures, unemployment benefits and production subsidies by lump-sum taxes. Monetary policy sets the short term nominal interest rate.

\subsection{Labor market search and matching}

As already mentioned, there are three different types of households: high and low-skilled workers and entrepreneurs, who all have constant masses $\varphi^{k}, k \in\{H, L, E\}$. We assume no transitions across those household types. In addition, the assumption of full insurance within a particular type allows us to model each type as a representative household splitting its time endowment between employment $n_{t}^{k}$, unemployment $u_{t}^{k}$, and inactivity (enjoying leisure) $l_{t}^{k}$. For simplicity, it is assumed that the entrepreneur types do not work, and only consume. The population size is normalized to one, i.e. $\sum_{k} \varphi^{k}=1$.

$$
1=n_{t}^{k}+u_{t}^{k}+l_{t}^{k} \quad k \in H, L
$$

Intermediate good firms post vacancies $v_{t}^{k}$ requiring different skills, which are then matched with unemployed job-searchers $U_{t}^{k}$ according to the following matching technology:

$$
m_{t}^{k}\left(v_{t}^{k}, U_{t}^{k}\right)=\psi^{k}\left(v_{t}^{k}\right)^{\varsigma}\left(U_{t}^{k}\right)^{1-\varsigma} \quad k \in\{H, L\}
$$

where $\psi^{k}$ is the matching efficiency parameter for a $k$ skilled unemployed. Aggregate measures of employment and unemployment are $N_{t}^{k}=\varphi^{k} n_{t}^{k}$ and $U_{t}^{k}=\varphi^{k} u_{t}^{k}$.

Labor market tightness $\theta_{t}^{k}$, vacancy filling probabilities $\nu_{t}^{k}$ and hiring probabilities $\mu_{t}^{k}$ are defined as follows:

$$
\begin{aligned}
\theta_{t}^{k} & =\frac{v_{t}^{k}}{U_{t}^{k}} & k \in H, L \\
\nu_{t}^{k} & =\frac{m_{t}^{k}}{v_{t}^{k}} & k \in H, L \\
\mu_{t}^{k} & =\frac{m_{t}^{k}}{U_{t}^{k}}=\psi^{k}\left(\theta_{t}^{k}\right)^{\varsigma} & k \in H, L
\end{aligned}
$$

consumption inequality between high and low-skilled workers. However, apart from the dynamics of consumption inequality, the results we present here are robust to the assumption of complete markets. 
An exogenous separation rate $\sigma^{k}$ signals the fraction of employed workers losing their job, who then become unemployed. Unemployed agents either find a job, stay unemployed or exit the labor force. As a result, the transition dynamics between different labor market status can be expressed as:

$$
N_{t+1}^{k}=\left(1-\sigma^{k}\right) N_{t}^{k}+\underbrace{\mu_{t}^{k} U_{t}^{k}}_{m_{t}^{k}} \quad k \in H, L
$$

Participation in the labor force is chosen by a given-skilled household (from (1), we have: $1-l_{t}^{k}=$ $u_{t}^{k}+n_{t}^{k}$ ). However, while the household can only decide to start searching for a job (going from inactive to unemployed), getting a job is constrained by search and matching frictions. Therefore, $n_{t}^{k}$ are pre-determined (state) variables at time $t$, implying that the participation margin can only be adjusted through choosing $u_{t}^{k}$. Then, the choice of $u_{t}^{k}$ can affect future employment through the hiring probabilities $\mu_{t}^{k}$ in (5). Similarly, the intermediate firm cannot decide directly how many workers to employ in a given period, but it can only affect future employment levels through its current posted vacancies $v_{t}^{k}$ (as it also affects vacancy filling probabilities $\nu_{t}^{k}$ through labor market tightness $\theta_{t}^{k}$ in (4)). Once these choices are made by households and firms, and given the pre-determined levels of $n_{t}^{k}$, future flows into employment are governed by the laws of motion (6), which will act as constraints on the household's and firm's decision problems.

This also shows that there are two channels through which the different labor market status in our setup interact endogenously with the rest of the economy. One is the participation choice of the household through $u_{t}^{k}$, and the other one is the vacancy posting decision of intermediate firms $v_{t}^{k}$. Both take into account future desired levels of employment $n_{t+1}^{k}$, which in turn are subject to the constraints imposed by SAM frictions. The potential asymmetry in SAM frictions across skills $k \in\{H, L\}$ are captured by $k$-specific parameters $\sigma^{k}, \psi^{k}$.

\subsection{Households}

The three different household types (i.e. $k \in\{H, L, E\}$ ) exhibit some common features. They all maximize lifetime utility, which is a separably additive function of consumption $c_{t}^{k}$ and leisure $l_{t}^{k}$. The intertemporal elasticity of substitution is $\frac{1}{\eta}$ for everyone. Lump sum taxes $t^{k}$ are collected from the households by the government. The aggregate price level of final consumption goods is $P_{t}$.

The three households can trade with each other sequentially through complete spot financial markets, i.e. in a full set of one-period state-contingent claims $z_{t+1}^{k}\left(s^{t}, s_{t+1}\right)$. These claims pay one unit of currency in $t+1$ if the particular state $s_{t+1}$ occurs, and zero otherwise, and their time $t$ nominal price is $q_{t, t+1}\left(s_{t+1} \mid s^{t}\right)$, given shock history $s^{t}$. Similar Arrow securities are also traded among individuals within a particular household type. This leads to full insurance against idiosyncratic income shocks stemming from endogenous SAM frictions-induced unemployment 
risk. This complete markets assumption allows us to model a continuum of potentially different consumers as single households representative of their types (akin to big families). ${ }^{9}$

\subsubsection{Entrepreneurs}

Entrepreneurs do not participate in the labor market, and for simplicity it is assumed that they derive no utility from leisure. In addition to trading in state contingent securities $z_{t+1}^{E}\left(s^{t}, s_{t+1}\right)$, they can also save by investing in physical capital $k_{t}{ }^{10}$. Investment $i_{t}$ also has to cover depreciation at rate $\delta$ and capital adjustment costs, the latter being governed by parameter, $\omega$. Entrepreneurs then rent capital out to intermediate firms at a rental rate $r_{t}$. They own the firms in the economy, so they receive all profits as dividends $d_{t}$, and equity is not traded with workers. Finally, they maximize utility subject to their budget constraint and the capital law of motion.

$$
\begin{gathered}
\max _{\left\{c_{t}^{E}, i_{t}, k_{t+1}, z_{t+1}^{E}\left(s^{t}, s_{t+1}\right)\right\}} E_{0} \sum_{t=0}^{\infty} \beta^{t} \frac{\left(c_{t}^{E}\right)^{1-\eta}}{1-\eta} \\
c_{t}^{E}+i_{t}+t_{t}^{E}+\frac{1}{P_{t}} \sum_{s_{t+1} \in \mathcal{S}} q_{t, t+1}\left(s_{t+1} \mid s^{t}\right) z_{t+1}^{E}\left(s^{t}, s_{t+1}\right) \leq r_{t} k_{t}+\frac{z_{t}^{E}\left(s^{t}\right)}{P_{t}}+d_{t} \\
i_{t}=k_{t+1}-(1-\delta) k_{t}+\frac{\omega}{2}\left(\frac{k_{t+1}}{k_{t}}-1\right)^{2} k_{t}
\end{gathered}
$$

The solution to this problem is the standard Euler equation, $\left(c_{t}^{E}\right)^{-\eta}=\beta E_{t}\left\{\left(c_{t+1}^{E}\right)^{-\eta} \frac{R_{t}}{\Pi_{t+1}}\right\}$, and a no-arbitrage condition connecting the ex ante real interest rate $\frac{R_{t}}{E_{t} \Pi_{t+1}}$ to the return on capital (after depreciation and capital adjustment costs). Gross inflation is defined as $\Pi_{t}=P_{t} / P_{t-1}$, while $R_{t}=\left[\sum_{s_{t+1}} q_{t, t+1}\left(s_{t+1} \mid s^{t}\right)\right]^{-1}$ is the gross nominal interest rate of a risk-free nominal bond. For the full set of equilibrium conditions, we refer the reader to the Online Appendix.

\footnotetext{
${ }^{9}$ Notice that, since we have full insurance not only within a skill type but also across skill types, we could have modeled the whole economy with a single representative household whose members have different skills. This would not change the dynamics in any significant way. However, we opted for making the distinction between household types, as this leads to a more "natural" distribution of steady state consumption corresponding to skill differences, rather than the arbitrary uniform allocation under a single household. This also leaves open the possibility of readily introducing incomplete markets between different skill types and some welfare analysis (for an attempt in this direction, see Dolado et al. (2018)).

${ }^{10}$ Notice that all variables in the model are naturally functions of the shock history, to ease notation we are not making this explicit in the equations describing the model.
} 


\subsubsection{Workers}

Workers of each type maximize utility subject to the budget constraint and constraints on employment flows imposed by SAM frictions (6). Their problem can be summarized as follows:

$$
\begin{aligned}
\max _{\left\{c_{t}^{k}, z_{t+1}^{k}\left(s^{t}, s_{t+1}\right), u_{t}^{k}, n_{t+1}^{k}\right\}} E_{0} \sum_{t=0}^{\infty} \beta^{t}\left[\frac{\left(c_{t}^{k}\right)^{1-\eta}}{1-\eta}+\Phi^{k} \frac{\left(1-n_{t}^{k}-u_{t}^{k}\right)^{1-\xi}}{1-\xi}\right] \quad k \in H, L \\
c_{t}^{k}+t_{t}^{k}+\frac{1}{P_{t}} \sum_{s_{t+1} \in \mathcal{S}} q_{t, t+1}\left(s_{t+1} \mid s^{t}\right) z_{t+1}^{k}\left(s^{t}, s_{t+1}\right) \leq w_{t}^{k} n_{t}^{k}+\varkappa^{k} u_{t}^{k}+\frac{z_{t}^{k}\left(s^{t}\right)}{P_{t}} \quad k \in H, L \\
n_{t+1}^{k}=\left(1-\sigma^{k}\right) n_{t}^{k}+\mu_{t}^{k} u_{t}^{k} \quad k \in H, L
\end{aligned}
$$

The elasticity of labor supply is influenced by $\xi$, while $\Phi^{k}$ governs the weight of the leisure of each skill type in their utility. Workers can trade in state-contingent Arrow securities $z_{t+1}^{k}\left(s^{t}, s_{t+1}\right)$. Employed members of the household bring home a real wage $w_{t}^{k}$, while unemployed members get inflation-indexed unemployment benefits $\varkappa^{k}$ which are assumed to be time invariant.

The first-order conditions to the workers' problem can be found in the Online Appendix, which describes consumption-saving and labor supply decisions ${ }^{11}$. Due to complete financial markets, there is full insurance, i.e. consumption inequality across different skill types $k \in\{H, L\}$ does not fluctuate, but real wages, labor force participation and employment do in general move differently. Note, however, that even under complete markets there is consumption inequality since different households enjoy different consumption levels in the steady state (through different wages, rent, benefits, initial wealth).

\subsection{Intermediate goods firms}

A continuum of perfectly competitive firms produces a homogeneous intermediate good $y_{t}$, using high and less-skilled labor $N_{t}^{k}$ and aggregate capital $K_{t}=\varphi^{E} k_{t}$ as inputs. Just like in the households' problem, $N_{t}^{k}$ are state variables, given by matches and employment levels from the previous period. It is only next period's employment levels $N_{t+1}^{k}$ which can be influenced by choosing how many vacancies $v_{t}^{k}$ to post. This influence is subject to the same SAM frictions as in the case of the household, however, (6) is now reformulated by plugging in (4) to reflect how vacancies are affecting the number of matches. ${ }^{12}$ Therefore, the firm's problem becomes

\footnotetext{
${ }^{11}$ The law of motion for employment (6) is expressed here in per capita terms, i.e. divided by the mass of workers $\varphi^{k}$. Using laws of motion for employment (6) means that the household does not take the number of matches as given, but takes into account the effect of its unemployment decisions on matches, at least partially. It ignores, however, the full effect of its decisions on matches. In particular, its unemployment decisions also affect hiring probabilities $\mu_{t}^{k}$ through (5), which the household takes as given in the above formulation; see Brückner and Pappa (2012). The full effect would be taken into account only if we replaced (2) into (6), instead of using the formulation with hiring probabilities.

${ }^{12}$ Also, as in the case of the household, the firm does not take into account the full effect of its vacancy choices on the number of matches. In particular, it disregards the effect on vacancy filling probabilities through (4).
} 
dynamic:

$$
\begin{aligned}
& V^{F}\left(N_{t}^{H}, N_{t}^{L}, s_{t}\right)=\max _{K_{t}, N_{t+1}^{H}, N_{t+1}^{L}, v_{t}^{H}, v_{t}^{L}} x_{t} F\left(K_{t}, N_{t}^{H}, N_{t}^{L}\right)-r_{t} K_{t}-\sum_{k \in\{H, L\}}\left(w_{t}^{k} N_{t}^{k}+\kappa v_{t}^{k}\right)+ \\
& +E_{t} \Lambda_{t+1} V^{F}\left(N_{t+1}^{H}, N_{t+1}^{L}, s_{t+1}\right) \\
& N_{t+1}^{k}=\left(1-\sigma^{k}\right) N_{t}^{k}+\nu_{t}^{k} v_{t}^{k} \quad k \in\{H, L\}
\end{aligned}
$$

where $\Lambda_{t+1}=\beta\left(c_{t+1}^{E} / c_{t}^{E}\right)^{-\eta}$ is the stochastic discount factor of the entrepreneurs, reflecting the ownership of the firm. The real price of intermediate goods $x_{t}$ is taken as given by the firm this constitutes real marginal costs for retail firms. Posting vacancies has a unit cost of $\kappa$.

The production function is defined as

$$
Y_{t}=F\left(K_{t}, N_{t}^{H}, N_{t}^{L}\right)=A_{t}\left[\phi\left[\lambda K_{t}^{\gamma}+(1-\lambda)\left(N_{t}^{H}\right)^{\gamma}\right]^{\frac{\alpha}{\gamma}}+(1-\phi)\left(N_{t}^{L}\right)^{\alpha}\right]^{\frac{1}{\alpha}}
$$

Following Krusell et al. (2000) and Lindquist (2004), our baseline production function (7) is a nested CES composite of production factors, where we can separately control the elasticity of substitution between capital and high skilled labor, $\varrho_{k, n^{H}}$ on the one hand, and between capital and low skilled labor $\varrho_{k, n^{L}}$ on the other. The structure of the nesting implies that the elasticity of substitution between high and low-skilled labor must be the same as between capital and lowskilled labor $\varrho_{n^{H}, n^{L}}=\varrho_{k, n^{L}}$. The capital intensity of the "skilled input bundle" is controlled by $\lambda$, while $\phi$ represents the "skill intensity" of total production. The elasticities of substitution are governed by parameters $\gamma$ and $\alpha$, and can be defined as $\varrho_{k, n^{H}}=\frac{1}{1-\gamma}$, and $\varrho_{k, n^{L}}=\varrho_{n^{H}, n^{L}}=\frac{1}{1-\alpha}$. We restrict these elasticities to be positive in order to maintain strict quasi-concavity of the production function. This means that $\alpha, \gamma \leq 1$.

Capital-skill complementarity (CSC) is captured in the following way:

- $0<\varrho_{k, n^{H}}<1$ represents $\operatorname{CSC}(\gamma<0$, with larger absolute values corresponding to a higher degree of complementarity)

- $1<\varrho_{k, n^{L}}$ shows the substitutability of less-skilled labor with the skilled inputs $(0<\alpha \leq 1$ with larger values corresponding to a higher degree of substitution and $\alpha=1$ meaning perfect substitutes)

- $\varrho=1$ corresponds to a CD production function, with a unit elasticity of substitution $(\gamma, \alpha=0)$

This follows from Koczan et al. (2017), who define production factors as complements whenever their elasticity of substitution is below unity. In such a case, a reduction in the relative price of one of the factors increases the income share of the other factor, and vice versa for substitutes. Lindquist (2004) uses a less strict definition: based on the following formula, he shows that as long as $1 \geq \alpha>\gamma$, a rise in the stock of capital will ceteris paribus raise the relative marginal 
product of skilled labor $\frac{F_{N, t}^{H}}{F_{N, t}^{L}}$, and this is what he calls CSC effect. ${ }^{13}$ It also follows that a rise in low-skill employment relative to high-skill employment raises the marginal product of high-skilled workers, which is called the relative supply effect.

$$
\frac{F_{N, t}^{H}}{F_{N, t}^{L}}=(1-\lambda) \frac{\phi}{1-\phi}\left[\lambda\left(\frac{K_{t}}{N_{t}^{H}}\right)^{\gamma}+(1-\lambda)\right]^{\frac{\alpha-\gamma}{\gamma}}\left(\frac{N_{t}^{L}}{N_{t}^{H}}\right)^{1-\alpha}
$$

In order to see the effects of CSC relative to the case where it is absent, we can change parameters $\gamma$ and $\alpha$, but we also need a different benchmark production function, the structure of which allows for controlling the elasticity of substitutions separately between capital and any labor input, and between the two different types of labor.

$$
\widetilde{F}\left(K_{t}, N_{t}^{H}, N_{t}^{L}\right)=A_{t} K_{t}^{\iota}\left[\varpi\left(N_{t}^{H}\right)^{v}+(1-\varpi)\left(N_{t}^{L}\right)^{v}\right]^{\frac{1-\iota}{v}}
$$

where, as is well known, the assumed CD structure between capital and composite labor implies that these inputs are neither complements nor substitutes, and their income shares are constant, with $\iota$ denoting the share of capital. The two different types of labor are perfect substitutes when $v=1$. Notice that, with equal intensity $\varpi=0.5$, labor is basically homogeneous.

Finally, aggregate TFP in (7) follows an exogenous $\mathrm{AR}(1)$ process: $\ln A_{t}=\rho_{a} \ln A_{t-1}+\varepsilon_{t}^{a}$.

\subsection{Wage bargaining}

Workers and intermediate firms split the surplus from a match according to Nash-bargaining. Wages are negotiated separately on the high and low-skill labor markets.

$$
\begin{gathered}
\max _{w_{t}^{k}} \vartheta^{k} \ln \left(V_{t}^{E, k}\right)+\left(1-\vartheta^{k}\right) \ln \left(V_{t}^{F, k}\right) \quad k \in H, L \\
V_{t}^{E, k}=\frac{\partial \mathcal{L}}{\partial n_{t}^{k}}=\lambda_{t}^{c, k} w_{t}^{k}-\Phi^{k}\left(l_{t}^{k}\right)^{-\xi}+\left(1-\sigma^{k}\right) \lambda_{t}^{n, k} \\
V_{t}^{F, k}=\frac{\partial V^{F}\left(N_{t}^{k}\right)}{\partial N_{t}^{k}}=x_{t} F_{N, t}^{k}-w_{t}^{k}+\left(1-\sigma^{k}\right) \frac{\kappa}{\nu_{t}^{k}}
\end{gathered}
$$

where $V_{t}^{E, k}$ is the marginal value for the household of being employed, and $V_{t}^{F, k}$ is the value for the firm of a filled job. $\mathcal{L}$ is the Lagrangian of the household, $V^{F}$ is the value function of the firm, while the weights $\vartheta^{k}$ represent the bargaining power of workers in each labor market.

The solution to this problem yields the real wage $w_{t}^{k}$ :

$$
w_{t}^{k}=\vartheta^{k}\left[x_{t} F_{N, t}^{k}+\left(1-\sigma^{k}\right) \frac{\kappa}{\nu_{t}^{k}}\right]+\frac{1-\vartheta^{k}}{\left(c_{t}^{k}\right)^{-\eta}}\left[\Phi^{k}\left(l_{t}^{k}\right)^{-\xi}-\left(1-\sigma^{k}\right) \lambda_{t}^{n, k}\right]
$$

where $\lambda_{t}^{n, k}$ is the Lagrange-multiplier on the SAM-constraint (6) in the workers' problem.

\footnotetext{
${ }^{13}$ Unlike the work of Koczan et al. (2017) and Lindquist (2004), in our model SAM frictions establish a wedge between the wage and the marginal product of labor, but the two are still closely related. Therefore, the above argument can be applied to the skill premium as well.
} 


\subsection{Retail firms}

We have a continuum $i \in[0,1]$ of monopolistically competitive retail firms, each of which buys $y_{t}(i)$ amount of the homogeneous intermediate good $Y_{t}$, and produces a differentiated product $y_{t}^{r}(i)$ with a linear technology, i.e. $y_{t}^{r}(i)=y_{t}(i)$. These differentiated products are then assembled to become final goods $Y_{t}^{r}$ according to a CES aggregator:

$$
Y_{t}^{r}=\left[\int_{0}^{1} y_{t}^{r}(i)^{\frac{\epsilon-1}{\epsilon}} d i\right]^{\frac{\epsilon}{\epsilon-1}}=\left[\int_{0}^{1} y_{t}(i)^{\frac{\epsilon-1}{\epsilon}} d i\right]^{\frac{\epsilon}{\epsilon-1}}=Y_{t}
$$

where the last equality follows from symmetry (each retailer buys exactly the same amount of intermediate $y_{t}(i)$ ), so that the $r$ superscript can be dropped as there will be as much of the final goods as of intermediate goods. Finally, $\epsilon$ denotes the elasticity of substitution between different products.

Retail firms take as given the relative price $x_{t}$ of the intermediate good, which is basically their real marginal cost. This depends neither on $i$ (since intermediate goods are homogeneous, so retail firms are competitive buyers), nor on the amount of goods used (since all the retail firms are infinitesimally small). Due to differentiation, retailers have pricing power in setting the price of their own product $p_{t}(i)$, but take the aggregate price level $P_{t}$ as given. The latter is defined as $P_{t}=\left[\int_{0}^{1} p_{t}(i)^{1-\epsilon} d i\right]^{\frac{1}{1-\epsilon}}$.

In setting their price, retailers are constrained by Calvo-type nominal rigidities, so that, in every given period, a fraction $\chi$ of them cannot adjust prices. The $(1-\chi)$ fraction of firms, who are able to adjust prices in a given period, will choose the new price, $\left(p_{t}^{*}(i)\right)$, so as to maximize the real present value of expected future profits, taking into account nominal rigidities and also the price elastic demand of households.

$$
\begin{gathered}
p_{t}^{*}(i) \equiv \underset{p_{t}(i)}{\arg \max } E_{t} \sum_{s=0}^{\infty} \chi^{s} \Lambda_{t+s}\left[\frac{p_{t}(i)}{P_{t+s}}-(1-\tau) x_{t+s}\right] y_{t+s}(i) \\
y_{t+s}(i)=\left(\frac{p_{t}(i)}{P_{t+s}}\right)^{-\epsilon} Y_{t+s}
\end{gathered}
$$

where $\tau$ is a production subsidy used by the government to eliminate the static distortion coming from monopolistic competition. Due to symmetry across retailers, all of them will choose the same price $p_{t}^{*} \equiv p_{t}^{*}(i)$. The solution to this problem yields:

$$
p_{t}^{*}=\underbrace{\frac{(1-\tau) \epsilon}{\epsilon-1}}_{(1-\tau) \mathcal{M}} E_{t} \frac{\sum_{s=0}^{\infty} \chi^{s} \Lambda_{t+s} y_{t+s}(i) \overbrace{P_{t+s} x_{t+s}}^{M C_{t}}}{\sum_{s=0}^{\infty} \chi^{s} \Lambda_{t+s} y_{t+s}(i)}
$$

Calvo-rigidities imply that the evolution of the aggregate price level follows

$$
P_{t}=\left[(1-\chi)\left(p_{t}^{*}\right)^{1-\epsilon}+\chi P_{t-1}^{1-\epsilon}\right]^{\frac{1}{1-\epsilon}}
$$




\subsection{Monetary and fiscal policies}

Monetary policy sets short term nominal interest rates on risk-free bonds following a standard Taylor rule, reacting to inflation deviations form target and (potentially) also to the deviations of aggregate output from its steady state value (the latter denoted with upper-bar).

$$
\frac{R_{t}}{\bar{R}}=\left(\frac{\Pi_{t}}{\bar{\Pi}}\right)^{\zeta^{\pi}}\left(\frac{Y_{t}}{\bar{Y}}\right)^{\zeta^{y}} e_{t}
$$

where $e_{t}$ captures a monetary policy shock which follows an $\mathrm{AR}(1)$ process $\ln e_{t}=\rho_{R} \ln e_{t-1}+\varepsilon_{t}^{R}$. Fiscal policy involves an exogenous (and wasteful) government consumption $G_{t}$, a production subsidy $\tau$ to retailers, and inflation indexed unemployment benefits $\varkappa^{k}$, all of which are financed by lump-sum taxes $T_{t}$, so that the government runs a balanced budget in every period.

$$
\begin{aligned}
T_{t} & =G_{t}+\tau x_{t} Y_{t}+\sum_{k \in\{H, L\}} \varkappa^{k} U_{t}^{k} \\
\ln G_{t} & =\left(1-\rho_{g}\right) \ln (\Gamma \bar{Y})+\rho_{g} \ln G_{t-1}+\varepsilon_{t}^{g}
\end{aligned}
$$

where $\Gamma$ is the steady state output share of government consumption. The distribution of lump-sum taxes is assumed to be equal, i.e. $t_{t}^{k}=T_{t}$ for $k \in\{H, L, E\}$, so that we have $T_{t}=\sum_{k} \varphi^{k} t_{t}^{k}=T_{t} \sum_{k} \varphi^{k}$

\subsection{Market clearing}

Since households can only trade assets with each other, and not with the government or foreign agents, the markets for each Arrow security clear as follows:

$$
\sum_{k \in\{E, H, L\}} \varphi^{k} z_{t+1}^{k}\left(s^{t}, s_{t+1}\right)=0 \quad \text { for } \forall s^{t}, s_{t+1} \in \mathcal{S}
$$

Combining the budget constraints of the households and the government (and using the asset market clearing condition) we get the goods market clearing condition. Final output is used for consumption, investment, government expenditures and posting vacancies.

$$
Y_{t}=C_{t}+I_{t}+G_{t}+\sum_{k \in\{H, L\}} \kappa^{k} v_{t}^{k}
$$

where $C_{t}=\sum_{k \in(H, L, E)} \varphi^{k} c_{t}^{k}$ and $I_{t}=\varphi^{E} i_{t}$.

\section{Calibration}

To make our analysis comparable to the existing theoretical models, we consider the model period to be one quarter. Parameters are calibrated to match targets related to the steady-state values of participation and unemployment rates - separately for the high and low-skill labor 


\begin{tabular}{|c|c|c|c|c|c|}
\hline \multicolumn{6}{|l|}{ Parameters } \\
\hline separation rate, $\mathrm{H}$ & $\sigma^{H}$ & 0.0245 & & & \\
\hline separation rate, $\mathrm{L}$ & $\sigma^{L}$ & 0.0562 & capital intensity of skills & $\lambda$ & 0.3500 \\
\hline matching efficiency, $\mathrm{H}$ & $\psi^{H}$ & 0.7200 & substitutability bw $\left(N^{H}, K\right)$ and $N^{L}$ & $\alpha$ & 0.4000 \\
\hline matching efficiency, L & $\psi^{L}$ & 0.4550 & capital-skill complementarity & $\gamma$ & -0.4902 \\
\hline matching elasticity & $\varsigma$ & 0.5000 & capital adjustment costs & $\omega$ & 4.0000 \\
\hline population weigth, $\mathrm{H}$ & $\varphi^{H}$ & 0.2100 & depreciation rate & $\delta$ & 0.0100 \\
\hline population weigth, L & $\varphi^{L}$ & 0.6900 & discount factor & $\beta$ & 0.9900 \\
\hline population weigth, E & $\varphi^{E}$ & 0.1000 & (inverse) intertemporal elasticity & $\eta$ & 2.0000 \\
\hline vacancy posting costs & $\kappa$ & 0.1300 & labor supply elasticity parameter & $\xi$ & 4.0000 \\
\hline unemployment benefits, $\mathrm{H}$ & $\varkappa^{H}$ & 0.2875 & elasticity of substitution bw goods & $\epsilon$ & 6.0000 \\
\hline unemployment benefits, L & $\varkappa^{L}$ & 0.2875 & nominal rigidities (Calvo) & $\chi$ & 0.8000 \\
\hline TFP shock persistence & $\rho_{a}$ & 0.8500 & st.st. output share of government & $\Gamma$ & 0.2000 \\
\hline fiscal shock persistence & $\rho_{g}$ & 0.7000 & Taylor-coefficient on inflation & $\zeta^{\pi}$ & 1.5000 \\
\hline monetary shock persistence & $\rho_{R}$ & 0.7000 & Taylor-coefficient on output & $\zeta^{y}$ & 0.0000 \\
\hline \multicolumn{3}{|c|}{ Parameters targeting st.st. } & \multicolumn{3}{|l|}{ Targeted steady states } \\
\hline utility weight of leisure, $\mathrm{H}$ & $\Phi^{H}$ & 0.0516 & participation rate, $\mathrm{H}$ & partic $^{H}$ & 0.6900 \\
\hline utility weight of leisure, L & $\Phi^{L}$ & 0.2157 & participation rate, $\mathrm{L}$ & partic $^{L}$ & 0.6600 \\
\hline bargaining power, $\mathrm{H}$ & $\vartheta^{H}$ & 0.6955 & unemployment rate, $\mathrm{H}$ & unemp $p^{H}$ & 0.0280 \\
\hline bargaining power, L & $\vartheta^{L}$ & 0.3740 & unemployment rate, $\mathrm{L}$ & unemp $p^{L}$ & 0.0780 \\
\hline production subsidy & $\tau$ & 0.1667 & real marginal costs & $x$ & 1.0000 \\
\hline skill intensity of production & $\phi$ & 0.4273 & wage premium & $w^{H} / w^{L}$ & 1.5306 \\
\hline \multicolumn{6}{|c|}{ Non targeted steady states } \\
\hline market tightness, $\mathrm{H}$ & $\theta^{H}$ & 1.3954 & \multirow[t]{2}{*}{ ratio of job finding rates } & \multirow[t]{2}{*}{$\mu_{t}^{H} / \mu_{t}^{L}$} & \multirow[t]{2}{*}{1.2803} \\
\hline market tightness, L & $\theta^{L}$ & 2.1317 & & & \\
\hline
\end{tabular}

Table 1: Parameters and selected steady state values. The 6 blue steady-state values are targeted by 6 red parameters

markets. In doing this, we set values so that they track the pre-crisis averages for the U.S. As explained earlier, high-skilled workers are regarded to have some college education. According to this classification 21 percent of our households are high-skilled workers, 69 percent are lowskilled workers and the remaining 10 percent is the share of entrepreneurs in the economy. In terms of the model variables, the targets correspond to

$$
\begin{aligned}
\operatorname{partic}^{k} & \equiv \frac{N^{k}+U^{k}}{\varphi^{k}} \\
\text { unemp }^{k} & \equiv \frac{U^{k}}{N^{k}+U^{k}}
\end{aligned}
$$

Parameters $\Phi^{k}, \vartheta^{k}$ for $k=H, L$, are calibrated so as to match the above targets. The exact values can be seen in the second panel of Table 1, with blue for targeted steady states and with red for calibrated parameters.

We assume symmetry in the matching elasticity $\varsigma$ for the matching functions, and in vacancy posting costs $\kappa$. The asymmetry in SAM frictions is captured by skill-specific parameters: we use the average quarterly values for the separation rates of high and low-skilled workers between 1979 and 2007 reported in Wolcott (2018) which, in line with Fallick and Fleischman (2004), results in $\sigma^{H}<\sigma^{L}$. Efficiencies are assumed to comply with $\psi^{L}<\psi^{H}$, in line with the evidence 
in Barnichon and Figura (2015), Wolcott (2018) and Eeckhout and Kircher (2018) that propose a theory of the labor market where firms choose both the size and quality of the workforce, and show that, in a competitive search equilibrium with large firms, high-skilled workers enjoy higher matching probabilities than less-skilled workers. Wolcott (2018), using the same definition as ours to classify low and high-skilled workers, reports a fall in the gap in labor tightness between the two groups of workers between 1979 and 2007. On average the tightness in the low-skill labour market during this period in the CPS data equals 2.13. The gap in tightness between the high and low-skilled depends on the definition of high-skill vacancies. Although not targeted, our steady state values for tightness match the estimates of Wolcott (2018) when the cutoff used to define high skilled vacancies in her sample equals 0.7. Also, these parameter values result in larger frictions for the low-skilled workers, making their steady-state hiring probabilities lower than those of the high skilled: $\bar{\mu}^{L}<\bar{\mu}^{H}$. As a result, the steady state ratio of job finding rates for high vs. low-skilled workers equals 1.28 in our calibration while in the CPS data this ratio equals 1.14 (see Wolcott (2018)). Similarly, vacancy filling probabilities are higher for high-skill vacancies, $\bar{\nu}^{L}<\bar{\nu}^{H}$. These values imply that it is relatively more costly for low-skilled households to increase their participation.

The non-equal share of different skill types in the population $\varphi^{k}$ and our skill-specific steadystate targets for employment variables result in further asymmetries for calibrated parameters. In particular, given their lower participation rate, the weight of leisure (inactivity) in the households' utility function will be higher for low-skilled workers $\Phi^{H}<\Phi^{L}$ (Appendix C.3 also presents a calibration with $\Phi^{H}=\Phi^{L}$ and shows that this does not affect our main results). Furthermore, the bargaining power of these workers will be lower than that of high-skilled workers, $\vartheta^{L}<\vartheta^{H}$, implying that low skilled workers capture a smaller share of the surplus as wage. This is in line with the structural estimates of these parameters provided by Cahuc et al. (2006) using matched employer-employee data for France. The latter feature mitigates the relative costliness of lowskilled workers as the firm is able to capture a larger share of the surplus created by filling a low-skill vacancy. In addition, and given the wage premium, a similar real amount of unemployment benefits $\varkappa^{k}$ results in some asymmetry in the wage replacement rate $\varkappa^{H} / w^{H}<\varkappa^{L} / w^{L}$. Such asymmetry is supported by the data. According to Fischer (2017), income replacement rates differ across US states with the norm across states being a 40-60 percent replacement rate with a maximum ceiling, implying that effective replacement rates are likely to be lower for workers with higher earnings.

Heterogeneity across workers not only originates from the labor market, but it also has to do with their different role in production, as captured by CSC. We set elasticities of substitution based on the estimates provided by Krusell et al. (2000) for the proposed CSC production function. This means $\frac{1}{1-\gamma}=0.67$ and $\frac{1}{1-\alpha}=1.67$, which makes high-skill labor complementary to capital, while low-skill labor becomes substitute. Under our baseline parameterization we calibrate a steady-state skill premium of $53 \%$, which corresponds to the average value in our data. Finally, the production subsidy is set to eliminate the static distortion coming from 
monopolistic competition $\tau=1 / \epsilon$ which makes the steady state real marginal cost (markup) $x$ equal to one.

Other parameters are set to standard values in the literature. In the Online Appendix we further investigate the sensitivity of our results when we vary parameters- such as the labor supply elasticity, the degree of nominal rigidities, capital adjustment costs and the coefficients in the Taylor rule.

\section{Theoretical results}

We log-linearize the model around its deterministic steady-state, and compute IRFs to various shocks under different scenarios and parameterizations. The details of the calculation of the steady state can be found in the Online Appendix.

\subsection{The effect of expansionary monetary policy shocks}

An expansionary monetary policy shock (100 bp. cut in the annualized nominal interest rate) stimulates aggregate demand, which leads to expanding output and inflationary pressures (see purple dashed lines in Figure 2). Reacting to stronger demand, firms increase their demand for capital and labor, which leads to rising investment and higher employment, together with higher wages and a larger rent on capital (notice that the initial drop in capital investment is due to crowding out by higher investment into opening vacancies). What happens in our labor market with SAM frictions is that firms start posting more vacancies while households raise their labor market participation in response to better job finding prospects. However, employment cannot suddenly react much (i.e. it is not a jump variable) being subject to SAM frictions according to (6), which is why most of the adjustment takes place through higher wages. This is a standard result in SAM models. As demand pressures run up against SAM frictions, the surplus from a match increases a lot. In other words, firms are willing to agree to a much higher wage during the Nash bargaining, since they are compensated by higher revenues.

Heterogeneity in our labor market (asymmetric SAM) and different roles in production due to CSC imply that high and low-skilled workers will not experience the same increase in labor income as a result of the interest rate shock. Under our baseline scenario an expansionary monetary policy shock leads to a rise in the skill premium $\frac{w_{t}^{H}}{w_{t}^{L}}$ of about $1.5 \%$. As shown in the left panel of Figure 3, this comes together with an increase in the income share $\frac{w_{t}^{H} N_{t}^{H}}{Y_{t}-\kappa v_{t}}$ for the high skilled at the expense of a decreasing income share for the low skilled. This means that the benefits of a monetary easing are not evenly distributed, with high-skilled workers getting relatively more of the increase in real income than do low-skilled workers - even though both types are better off in absolute terms. To the extent that the low skilled are poorer to begin with (as reflected by a steady-state skill premium of $53 \%$ ), a monetary expansion raises labor 

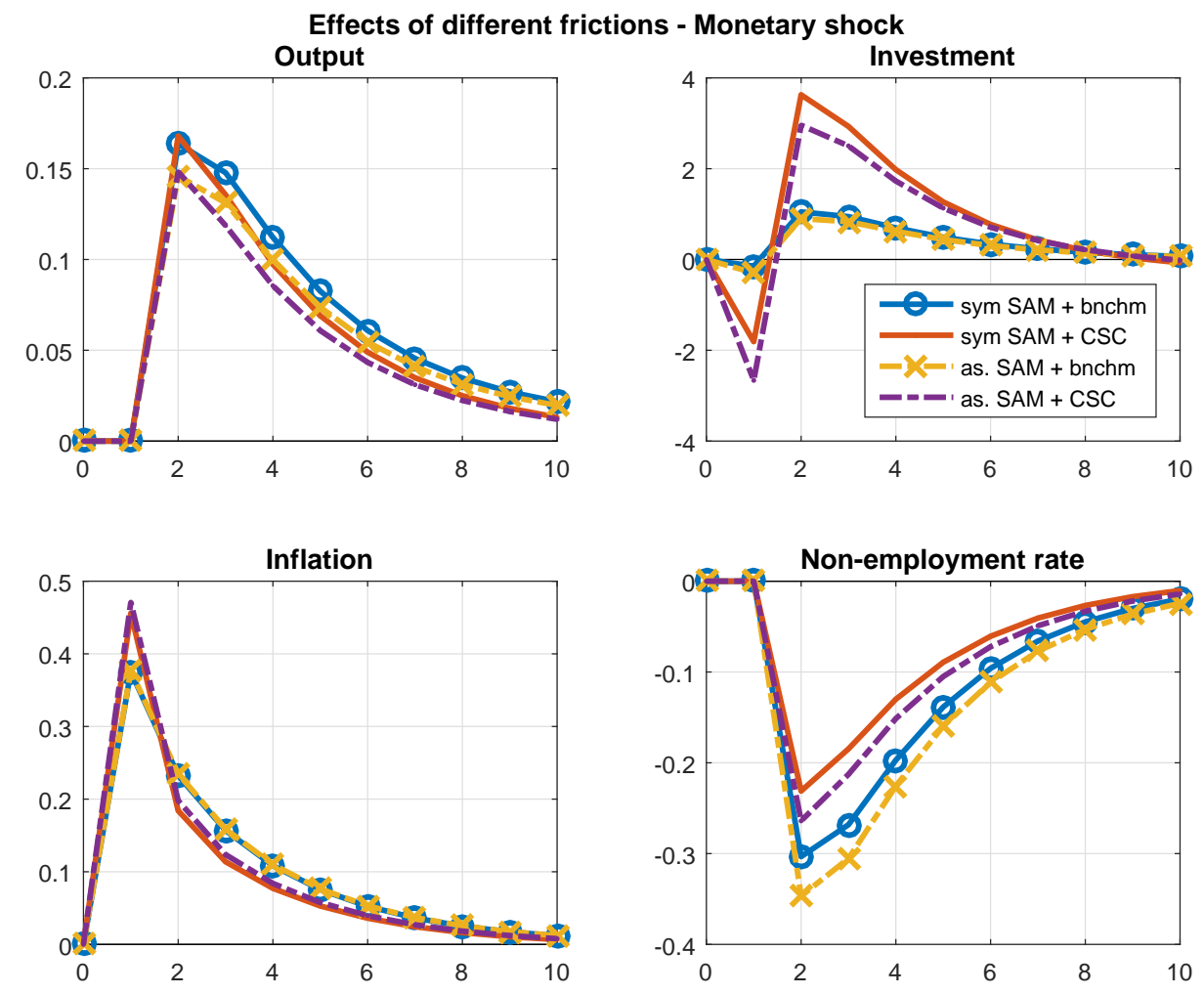

Figure 2: Effects of SAM asymmetry and CSC - aggregate variables

income inequality. The right panel of Figure 3 shows that the rise in the relative income share of high skilled labor $\frac{w_{t}^{H} N_{t}^{H}}{w_{t}^{L} N_{t}^{L}}$ is driven mainly by an increase in wages, while changes in employment have a negligible effect.

It is not clear, however, what the source of the increase in inequality is. In order to separately identify the effects of asymmetric SAM frictions on the one hand, and CSC on the other, we construct a benchmark case with symmetric SAM frictions and a standard CD production function, where high and low-skill labor inputs are perfect substitutes (as defined by equation (8)). Then we add either SAM asymmetry only or CSC only, so as to compare the effect of each of these two features against our benchmark. Finally, we add both sources of heterogeneity together to retrieve our original (baseline) scenario.

The results of this exercise are shown in Figures 2 for the aggregate variables. Blue circled lines represent our symmetric benchmark scenario. The results after introducing CSC are displayed in red solid lines. Changing the characteristics of the production function has an influence on the IRFs of aggregate variables. There is a somewhat smaller reduction of the non-employment rate $\frac{U_{t}+L_{t}}{N_{t}+U_{t}+L_{t}}$ and larger responses of investment when we assume a CSC production function. The effect of introducing only SAM asymmetries (and keeping the benchmark CD production function) is plotted with yellow crossed lines. IRFs of aggregate variables to expansionary monetary shocks are essentially identical to the benchmark (blue circled line) case, suggesting that labor market heterogeneity does not have significant consequences at the macro level when the benchmark production technology is CD. 


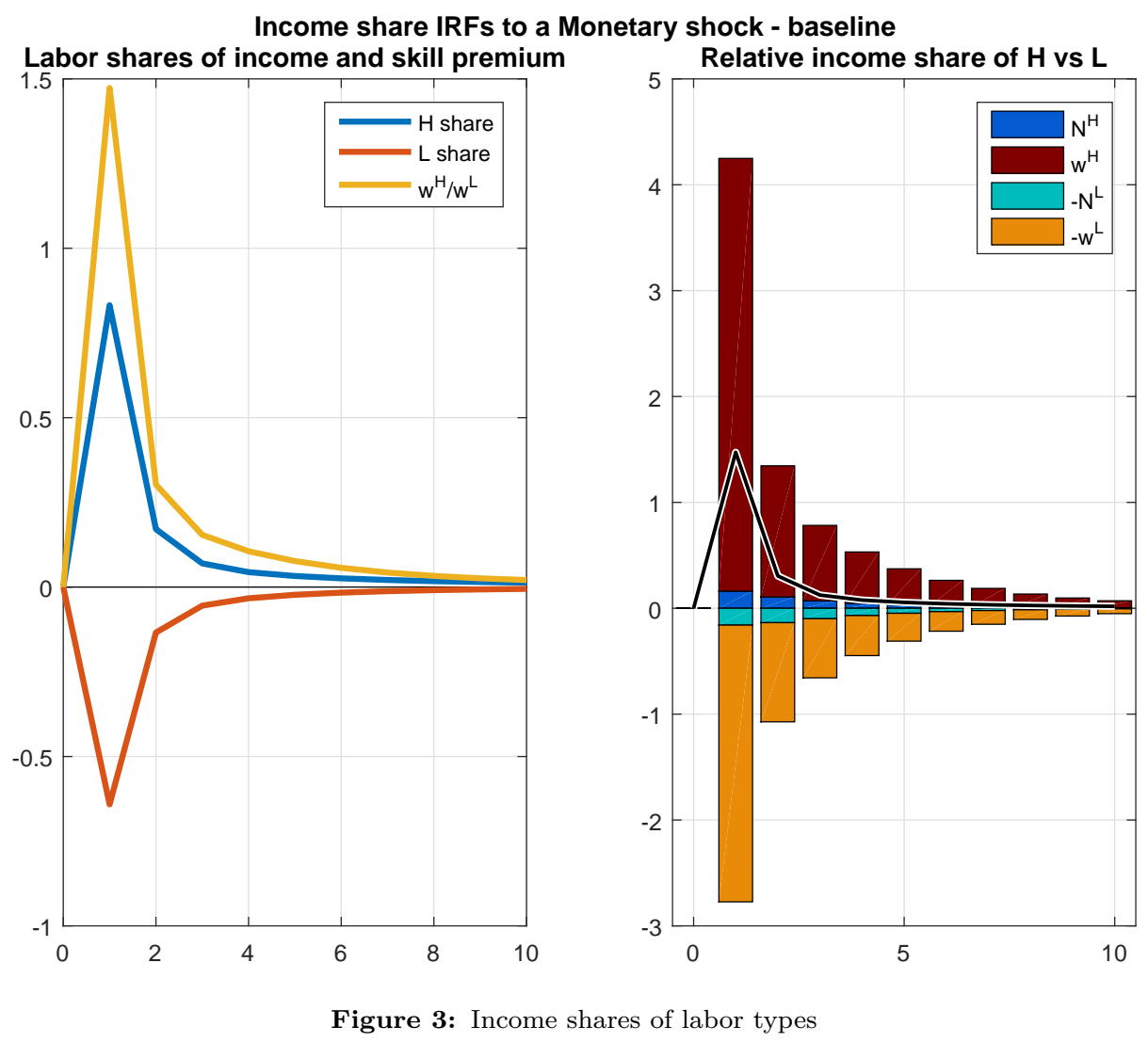

In Figure 4 we depict relative measures between high and low-skilled workers. The relative income share of high-skilled workers increases in the presence of CSC (red solid line). Similarly, SAM asymmetries induce a comparable increase on the responses of high vs. low-skill relative variables (yellow crossed line). Both assumed asymmetries increase the skill premium roughly by $0.4 \%$. The non-employment rate of high-skilled workers falls more relative to the case of no SAM asymmetries and their participation rate changes similarly in both scenarios. Yet, the magnitudes of these employment changes are small, implying that most of the rise in the relative labor income share of high-skilled workers is driven by the wage premium. Finally, we introduce CSC on top of SAM asymmetry, leading to responses which are plotted with purple dashed lines in Figure 4. The interaction of asymmetric SAM frictions with CSC magnifies the effect of the latter, raising the skill premium after an expansionary monetary shock by $1.5 \%$. In other words, introducing CSC on its own, or SAM asymmetry alone leads to only a modest rise in the relative income share, while their interaction has a larger combined effect than the simple sum of their individual effects. We explore the underlying mechanism behind those responses in the next section.

\subsection{Dissecting the mechanism}

As we show in detail in the Online Appendix, log-linearizing the wage bargaining equation (9), and using "hats" to denote the $\log$ deviation of a variable from its steady state, i.e. $\widehat{f_{t}}=$ 

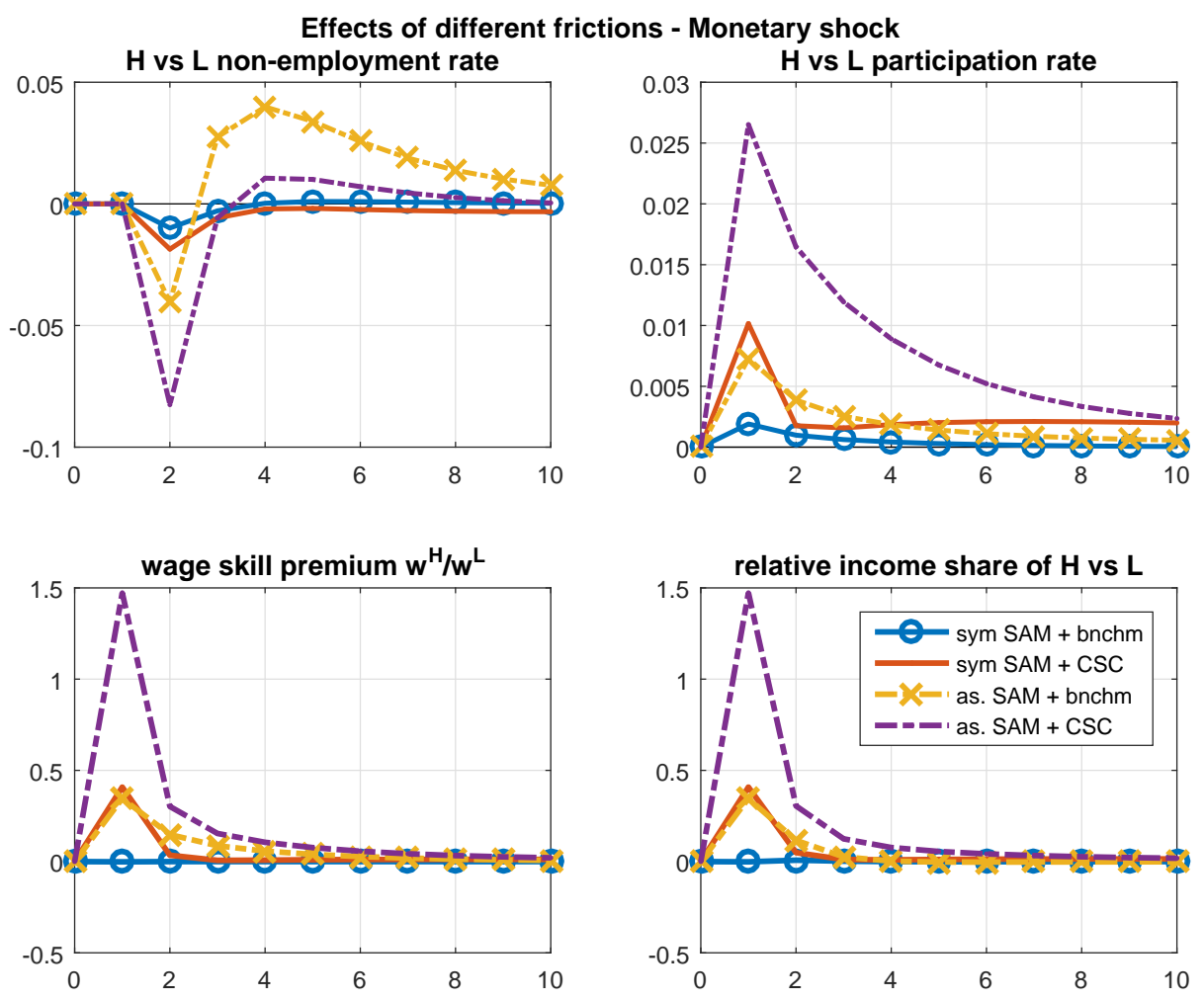

Figure 4: Effects of SAM asymmetry and CSC - relative variables

$\log f_{t}-\log f$, we can express the $\log$ deviations of the real wage of each skill type, $k$, as:

$$
\begin{aligned}
\widehat{w}_{t}^{k}=\underbrace{\frac{\vartheta^{k} x F_{N}^{k}}{w^{k}}}_{\alpha_{x}^{k}} \widehat{x}_{t}+\underbrace{\frac{\vartheta^{k} x F_{N}^{k}}{w^{k}}}_{\alpha_{F_{N}}^{k}} \widehat{F}_{N, t}^{k}+\underbrace{\frac{1-\sigma^{k}}{w^{k}}\left[(1-\varsigma) \frac{\vartheta^{k} \kappa^{k}}{\nu^{k}}+\varsigma \frac{\left(1-\vartheta^{k}\right) \lambda^{n, k}}{\lambda^{c, k}}\right]}_{\alpha_{\theta}^{k}} \hat{\theta}_{t}^{k}+ \\
+\underbrace{\frac{\eta\left(1-\vartheta^{k}\right)}{w^{k}}\left[\frac{\Phi^{k}\left(l^{k}\right)^{-\xi}}{\lambda^{c, k}}-\left(1-\sigma^{k}\right)\left(\frac{\lambda^{n, k}}{\lambda^{c^{k}}}+\frac{\varkappa^{k}}{\mu^{k}}\right)\right]}_{\alpha_{c}^{k}} \widehat{c}_{t}^{k}+ \\
+\underbrace{\xi \frac{\left(1-\vartheta^{k}\right) \Phi^{k}\left(l^{k}\right)^{-\xi}}{\lambda^{c, k} w^{k}}\left[\frac{\left(1-\sigma^{k}\right)}{\mu^{k}}-1\right]}_{\alpha_{l}^{k}} \widehat{l}_{t}^{k}= \\
=\alpha_{x}^{k} \widehat{x}_{t}+\alpha_{F_{N}}^{k} \widehat{F}_{N, t}^{k}+\alpha_{\theta}^{k} \widehat{\theta}_{t}^{k}+\alpha_{c}^{k} \widehat{c}_{t}^{k}+\alpha_{l}^{k} \widehat{l}_{t}^{k}
\end{aligned}
$$

Using equation (14) we can express the skill premium as:

$$
\begin{gathered}
\widehat{w}_{t}^{H}-\widehat{w}_{t}^{L}=\left(\alpha_{x}^{H}-\alpha_{x}^{L}\right) \widehat{x}_{t}+\left[\alpha_{F_{N}}^{H} \widehat{F}_{N, t}^{H}-\alpha_{F_{N}}^{L} \widehat{F}_{N, t}^{L}\right]+\left[\alpha_{\theta}^{H} \widehat{\theta}_{t}^{H}-\alpha_{\theta}^{L} \widehat{\theta}_{t}^{L}\right]+ \\
+\left[\alpha_{c}^{H} \widehat{c}_{t}^{H}-\alpha_{c}^{L} \widehat{c}_{t}^{L}\right]+\left[\alpha_{l}^{H} \widehat{l}_{t}^{H}-\alpha_{l}^{L} \widehat{l}_{t}^{L}\right]
\end{gathered}
$$

Equation (15) enables us to decompose the dynamics of the skill premium into the contributions of the various factors which drive this gap in the face of an expansionary monetary policy shock. Naturally, all dynamic changes are ultimately caused by the exogenous shock itself. This 
exercise rather sheds light on the different channels through which the shock propagates and affects wages. In particular, from the firm's side (through labor demand and the firm's surplus) the skill premium dynamics is affected by: demand pressures, as captured by the real marginal cost of retailers $\widehat{x}_{t}$ (the real sales price for intermediate firms); dynamic changes of skill-specific marginal products of labor $\widehat{F}_{N, t}^{k}$; and the tightness of the respective labor markets $\widehat{\theta}_{t}^{k}$. From the household's side (through labor supply and workers' surplus) skill premium dynamics are affected again by labor market tightness, by differing wealth effects, captured by $\widehat{c}_{t}^{k}$, and by labor force participation $\widehat{l}_{t}^{k}$.

The results of this decomposition are shown in Figure 5, which depicts how movements in each of these five variables contribute to the dynamics (IRFs) of the real wage $\widehat{w}_{t}^{k}, k=H, L$ and the skill premium $\widehat{w}_{t}^{H}-\widehat{w}_{t}^{L}$. As can be observed, the dominant factor in driving the response of real wages is the rise in aggregate demand pressures, as represented by movements in the real marginal costs for retailers $\widehat{x}_{t}$ (blue bars). Intuitively, as expanding aggregate demand raises the relative price at which intermediate goods can be sold, the surplus from matching workers to jobs increases, some of which will be reflected in higher real wages.

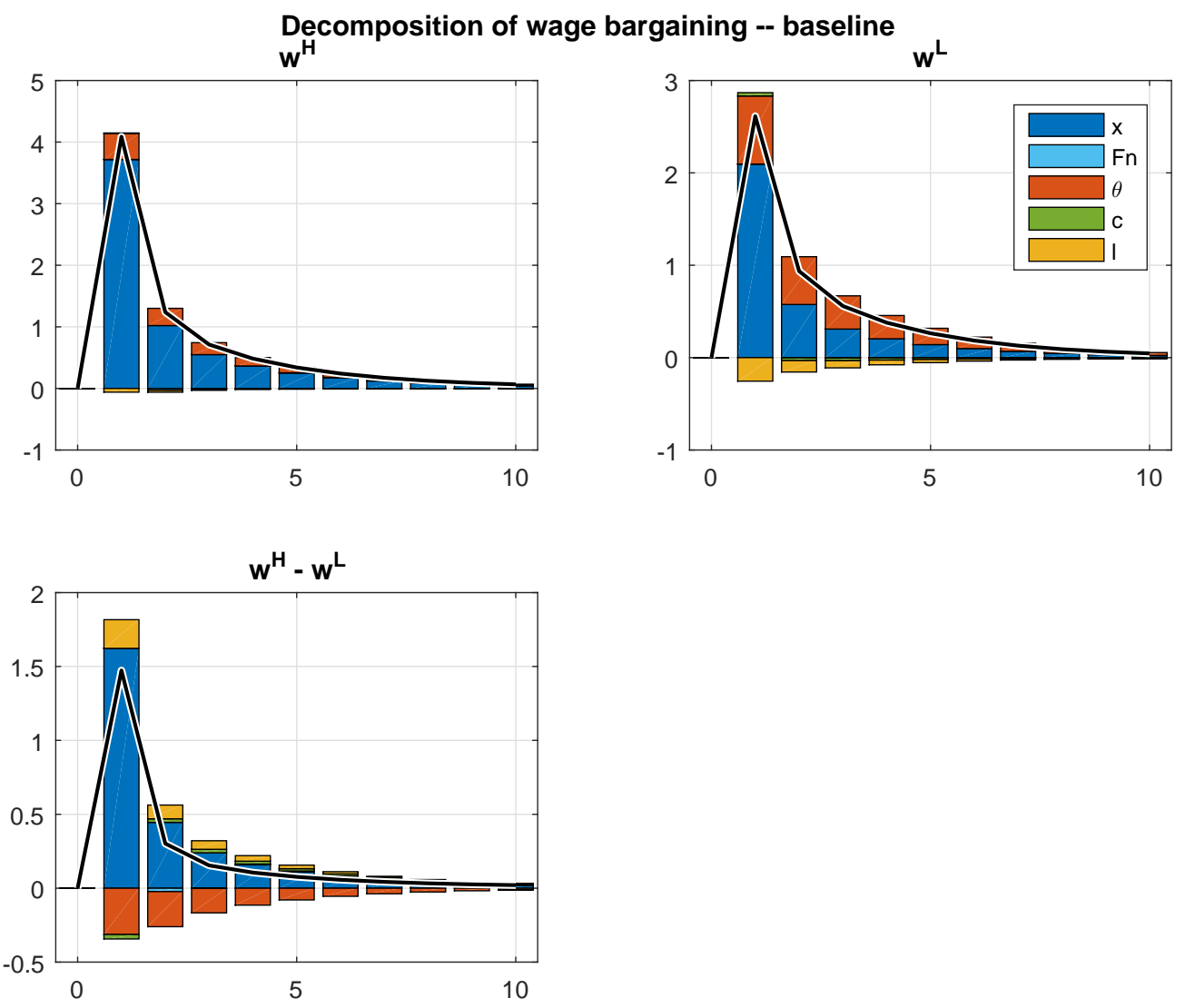

Figure 5: Decomposing real wage $\widehat{w}_{t}^{k}$ and wage premium $\widehat{w}_{t}^{H}-\widehat{w}_{t}^{L}$ dynamics based on equations (14) and (15).

As regards the dynamics of the skill premium, the bottom left panel of Figure 5 shows that the rise in aggregate demand pressures is again the factor contributing the most in the increases of the skill premium after a monetary expansion. This suggests that the increase in this wage gap is achieved predominantly through changes in the firm's surplus, which lead to adjustments 
in labor demand. By contrast, changes in labor supply and in worker's surplus (as captured by $\alpha_{c}^{k} \widehat{c}_{t}^{k}$ and $\alpha_{l}^{k} \widehat{l}_{t}^{k}$ ) play a comparatively smaller role. Labor market tightness $\widehat{\theta}_{t}^{k}$ (through its effect on vacancy filling and job finding rates) contributes noticeably, but still by a much lower amount than aggregate demand pressures. Notice that labor-market tightness pushes real wages upwards but its impulse is higher for less-skilled than for high-skilled workers. This explains why tighter labor markets on their own somewhat mitigate the rise in the skill premium.

We next conduct a similar decomposition of the skill premium for our alternative scenarios (without asymmetric SAM and/or CSC) to identify the channels through which the combined introduction of both features operates. Once more, for all the alternative scenarios considered, the most important contributor in (15) is still the term associated with aggregate demand pressures: $\left(\alpha_{x}^{H}-\alpha_{x}^{L}\right) \widehat{x}_{t}$. What significantly differ across scenarios are the two components of this term: i) the responsiveness of the skill premium to given demand pressures $\left(\alpha_{x}^{H}-\alpha_{x}^{L}\right)$; and ii) the dynamic responses of demand, captured by $\widehat{x}_{t}$.

First, the responsiveness coefficient $\left(\alpha_{x}^{H}-\alpha_{x}^{L}\right)$ increases ceteris paribus with more SAM-asymmetry and/or with a CSC production function, as illustrated in the bottom right panel of Figure 6 . The intuition is that a skill-intensive production structure, like our baseline CSC production function, raises the steady-state marginal product of high-skilled labor (and hence, the firm's surplus from skilled matches) relative to less-skilled labor, making firms tilt their hiring towards skilled workers. In the same vein, under asymmetric SAM frictions, firms prefer to hire workers with less frictions (the steady-state firm's surplus out of high-skilled jobs is larger). Lower matching efficiency in the unskilled sector makes it relatively more costly for firms to open lowskill vacancies and for households to enter this segment of the labor market. Likewise, the value of an unskilled match is relatively lower since the resulting job is more likely to be terminated and a subsequent match is less likely to take place. Notice that all of the above effects are due to differences in the steady-state values determining the responsiveness coefficients, and that the joint contribution of SAM asymmetry and CSC in this respect seems to be additive (bottom right panel in Figure 6).

However, in addition to the differences generated by steady-state properties of the model, CSC also introduces a dynamic demand amplification channel: apart from CSC making the skill premium more responsive to a given increase in demand pressures (through the coefficient $\alpha_{x}^{H}-$ $\alpha_{x}^{L}$ ), it also makes the rise in aggregate demand pressures $\widehat{x}_{t}$ themselves stronger, as evidenced by the top left panel in Figure 6. In other words, the dynamics of marginal costs also depend crucially on the assumed production function: with CSC, the reaction of $\widehat{x}_{t}$ doubles in response to the same shock - and it does so independently of the assumed symmetry of SAM frictions.

The intuition for this result is that, with CSC, the initial increase in high-skilled employment makes complementary capital more productive, encouraging a further rise in investment demand which leads to a multiplier loop for aggregate demand (in a similar fashion to how a traditional Keynesian Cross multiplier works through consumption). This dynamic amplification is missing 
IRFs and wage coeffs (monetary shock)
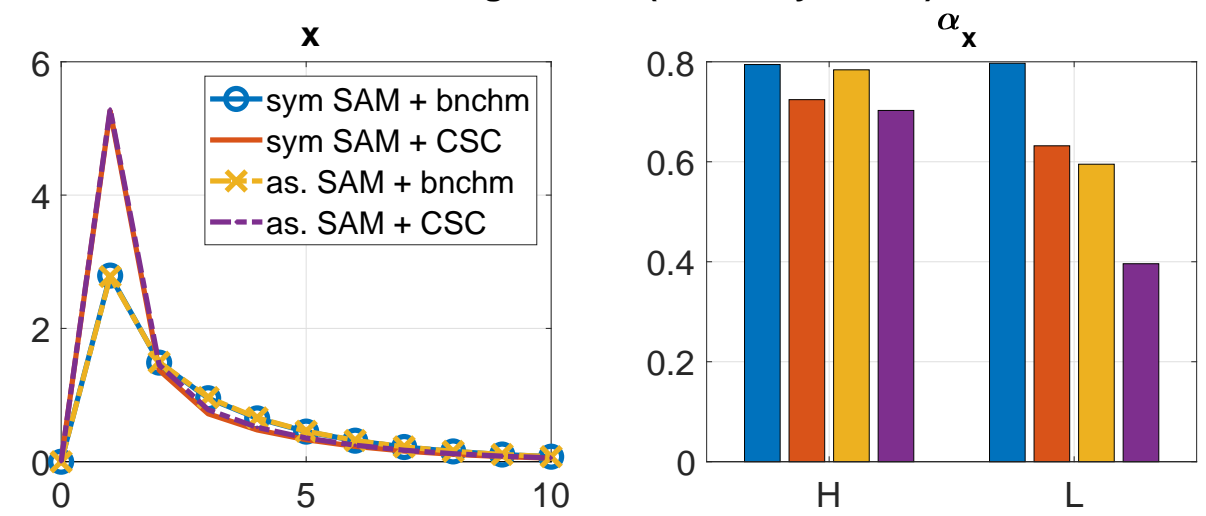

$\mathrm{H}$

$\mathrm{L}$
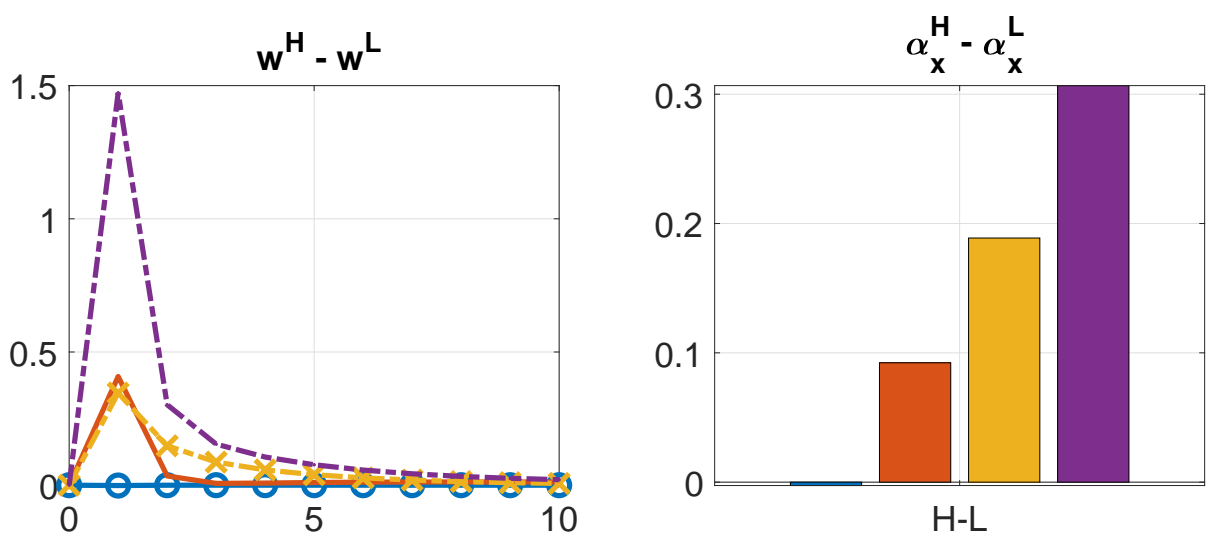

Figure 6: Comparing $\alpha_{x}^{k}$ and $\left(\alpha_{x}^{H}-\alpha_{x}^{L}\right)$, and $\widehat{x}_{t}$ and $\widehat{w}_{t}^{H}-\widehat{w}_{t}^{L}$ dynamics across different scenarios.

under a CD production function, where complementarity is not strong enough and the different types of labor are substitutes (even having SAM asymmetries wouldn't change this feature of CD production, since SAM frictions do not affect the marginal product of capital dynamically). ${ }^{14}$

Moreover, inspecting the skill premium dynamics helps understand why the dynamic amplification by CSC is magnified in an environment with asymmetric SAM frictions, relative to a symmetric SAM environment (see how differences between crossed yellow and dashed purple lines are larger than those between circled blue and solid red in the bottom left panel of Figure 6). This is due to the existence of another source of initial imbalance in relative labor demand to be multiplied by higher demand pressures (the one coming from SAM asymmetry in addition to CSC, and captured in the larger responsiveness coefficient). In sum, the dynamic amplification mechanism sheds light on why introducing both SAM asymmetry and CSC leads to a more powerful effect than the simple sum of the two channels alone.

\footnotetext{
${ }^{14}$ In the Online Appendix we also include variable capital utilization in the model. In this case, both effective capital and investment expand on impact after the shock. Yet, the responses of real marginal costs and the respective steady state coefficients that determine the skill premium responses are very similar to those in Figures 5 and 6 . The marginal product of labor plays a slightly bigger role (as more capital expansion makes complementary labor more productive), but this effect is much smaller than the role of aggregate demand pressures. This exercise shows that for the dynamic demand amplification channel to work, higher investment demand need not necessarily manifest itself in actually higher amounts of physical capital: demand pressures as evidenced by larger marginal costs are enough to engineer the CSC demand amplification channel.
} 
Lastly, we analyze the responses of the variables of interest to other demand shocks (e.g. government spending shocks) and cost-push shocks in Appendix C. The main finding here is that these alternative shocks do not change the previous results qualitatively: an increase in aggregate demand pressures raises the skill premium. Moreover, the skill premium rises more under CSC due to the dynamic demand amplification mechanism, and asymmetric SAM magnifies the effect of this channel. Quantitative differences appear, however, depending on how investment reacts to these shocks: positive shocks to government spending increase the skill premium by around 0.4 percent, which is less than the corresponding rise after a monetary shock (see Figures 10 and 11 in the Appendix). This is explained by a substantial crowding out of investment through higher public consumption. As a result, the pronounced fall in the capital stock mitigates the advantage of using complementary high-skill labor, therefore muting the response of the skill premium.

\subsection{Sensitivity analysis}

Since both CSC and asymmetric SAM are governed by various parameters, in this section we check how each of them affects our baseline results.

\subsubsection{Complementarity between capital and skilled labor}

CSC is captured in our model through the elasticity of substitution between capital and highskilled labor, $\frac{1}{1-\gamma}$. Figure 7 depicts responses of the key variables of interest when we vary this elasticity. Confirming our previous conclusions, a larger degree of CSC (i.e. lower elasticity of substitution, yellow dotted lines) favors high-skilled workers even more after an expansionary monetary shock. Looking at the wage dynamics decomposition and the term associated with aggregate demand pressures $\left(\alpha_{x}^{H}-\alpha_{x}^{L}\right) \widehat{x}_{t}$ we see that a higher complementarity manifests itself in this term less via differences in the responsiveness coefficient $\left(\alpha_{x}^{H}-\alpha_{x}^{L}\right)$, and more via larger increases of $\widehat{x}_{t}$ (see top left panel of Figure 7 ), implying that CSC mainly operates through the dynamic demand amplification channel rather than through steady-state differences in marginal products. ${ }^{15}$ In response to expanding aggregate demand, the initial rise in highskilled employment makes complementary capital more productive, inducing a further rise in investment demand and amplifying aggregate demand pressures $x_{t}$. Evidently, the increase in demand pressures is a positive function of CSC.

Conversely, decreasing complementarity (red dashed lines) results in the opposite changes. Notice that in the latter scenario we still maintain the relation $\frac{1}{1-\alpha}=1.67>\frac{1}{1-\gamma}=1.33$, which captures CSC in the sense defined by Lindquist (2004), even though capital and high-skillled

\footnotetext{
${ }^{15}$ The fact that in the bottom right panel of Figure 6 the responsiveness coefficient is significantly higher under CSC than under the benchmark CD production function has more to do with the skill-intensity of the production structure than with differences in the elasticity of substitution $\frac{1}{1-\gamma}$ itself.
} 


\section{IRFs and wage coeffs (monetary shock)}
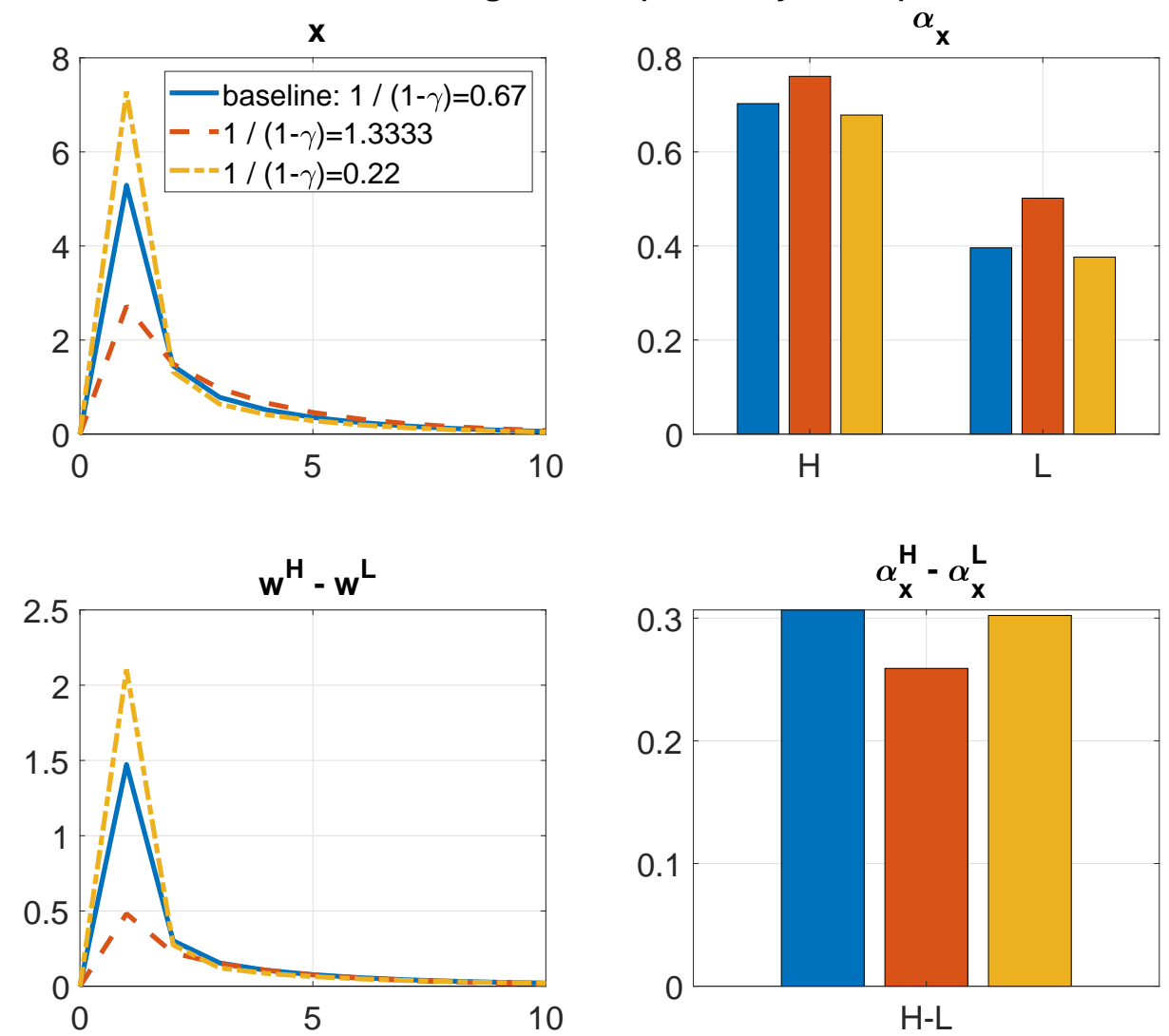

Figure 7: Comparing $\alpha_{x}^{k}$ and $\left(\alpha_{x}^{H}-\alpha_{x}^{L}\right)$, and $\widehat{x}_{t}$ and $\widehat{w}_{t}^{H}-\widehat{w}_{t}^{L}$ dynamics across different scenarios.

workers are now substitutes (but less so than capital and unskilled workers are). If we move to the point where $\frac{1}{1-\gamma}>\frac{1}{1-\alpha}$, then the CSC channel would switch sign and it would actually dampen the increase in the relative labor income share.

\subsubsection{The role of asymmetry in SAM-frictions}

In our baseline model there are several sources of asymmetry in SAM frictions. High and lowskilled workers differ in terms of matching efficiencies $\psi^{L}<\psi^{H}$, as well as in job separation rates $\sigma^{L}>\sigma^{H}$ and bargaining power $\vartheta^{L}<\vartheta^{H}$. In order to gauge the relative importance of each of these asymmetries in driving our results, we repeat the exercise in Section 5.1 with the modification that adding "SAM asymmetry" now means allowing for only one of the asymmetries at a time, rather than all of them jointly. ${ }^{16}$

Figure 8 displays the results of this exercise, with the top left panel plotting the baseline scenario

\footnotetext{
${ }^{16}$ When making each of these frictions "asymmetric", we are using the calibration in Table 1. The only exception is the worker's bargaining power, $\vartheta^{k}$, which is not a free parameter and it is already asymmetric in the otherwise "symmetric SAM + CSC" scenario $\left(\vartheta^{H}=0.71>\vartheta^{L}=0.62\right)$. This asymmetry stems from the fact that the surplus of high-skilled workers is higher with CSC. Given our calibration strategy, to obtain an even more asymmetric $\vartheta^{H}=0.79>>\vartheta^{L}=0.57$ (purple dashed line) we have changed the original population weights to $\varphi^{H}=0.1, \varphi^{L}=0.8$. Without CSC and any other source of SAM-asymmetry, changing the population weights will not affect the bargaining power, so we cannot engineer a "more asymmetric $\vartheta^{k}+$ benchmark" scenario.
} 

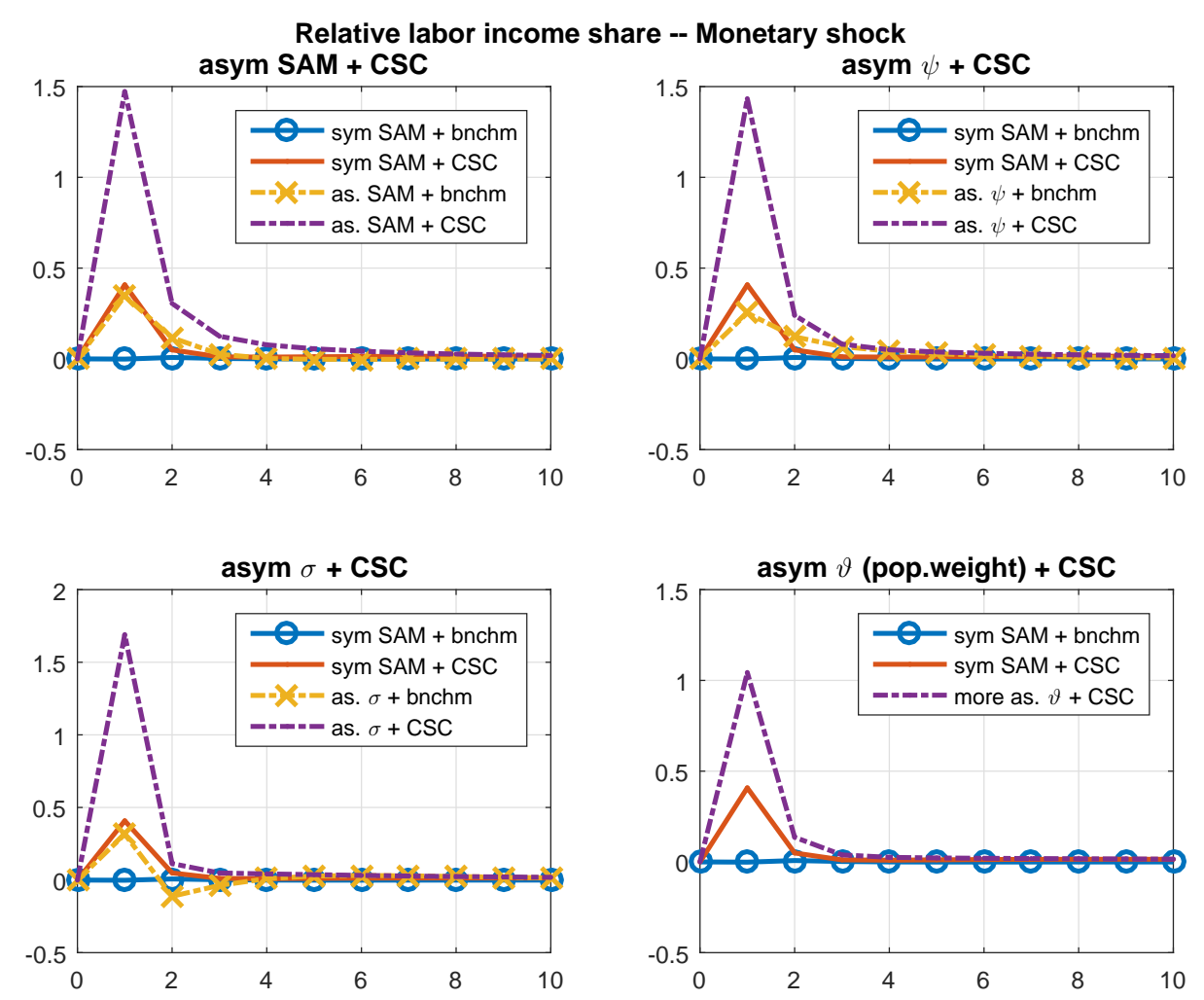

Figure 8: The effects of individual SAM asymmetries on the relative income share of high vs low skilled labor after an expansionary monetary policy shock

(same as the bottom right panel of Figure 4). Blue circled and red solid lines are the same across each panel as they capture scenarios with symmetric labor market frictions. As before, yellow crossed and purple dashed lines distinguish between production technology without or with CSC, respectively. Any type of labor market asymmetry intensifies the CSC amplification channel. Asymmetries in matching efficiency, $\psi^{k}$ and separation rates, $\sigma^{k}$ appear more important relative to asymmetries in the bargaining power, $\vartheta^{k}$. When firms weigh the costs and benefits of hiring an additional high-skilled worker, the short-run reduction in high-skilled labor adjustment costs (stemming from their higher matching efficiency) brings benefits to firms, thereby increasing the relative demand of these workers. Similarly, lower separation rates increase the continuation value and hence the surplus of a high-skilled match. These arguments apply both under CSC and $\mathrm{CD}$ production functions. Hence, the qualitative pattern of our previous results is preserved even when one considers each of the three sources of SAM-asymmetry separately.

\subsection{Different monetary policy strategies}

Besides analyzing the effects of an expansionary monetary policy shock on labor income inequality, it could also be important to know how different kinds of systematic monetary policy strategies perform in response to other shocks that could drive cyclical fluctuations. Despite the fact that our assumption of complete financial markets does not provide the most realistic setup for optimal policy analysis, some comparison can still be made of how different policy regimes 
manage to smooth cyclical fluctuations in labor income inequality in the face of various shocks. Based on our previous finding that aggregate demand pressures are the most important driver of the skill premium, we would expect that a monetary policy rule which manages to stabilize demand fluctuations (i.e. close the output gap) will also do well in terms of preventing the distributional consequences of these shocks.

In a basic New Keynesian model, for shocks exhibiting the so called divine coincidence, the central bank does not face any trade-off between stabilizing inflation and the welfare-relevant output gap (Blanchard and Galí, 2007). In such cases, strict inflation targeting (IT) is the optimal policy, which also stabilizes aggregate demand. For models like ours, including labor market frictions, Blanchard and Galí (2010) and Ravenna and Walsh (2011) show that the divine coincidence vanishes, but they argue that delivering price stability remains very close to the optimal policy. Indeed, in our model strict IT performs best in terms of stabilizing aggregate demand and the skill premium. This is also the case in the face of various shocks (including cost-push shocks which introduce a trade-off between inflation and output gap stabilization). Strict IT dominates other Taylor rules in this respect also without CSC. The insight for this result is that a strict commitment to price stability helps the central bank manage inflation expectations more efficiently and improve the trade-off along the Phillips Curve, so that a given change in the inflation rate requires a smaller sacrifice in terms of output deviations. ${ }^{17}$

\section{Conclusions}

In order to improve our understanding of the channels through which monetary policy affects labor income inequality, we have built a New Keynesian model with capital-skill complementarity (CSC) in the production function and asymmetric search and matching (SAM) frictions in the labor market between high and low-skilled workers. Our contribution here is to analyze a new mechanism through which monetary policy can affect labor income inequality: the assumption of a CSC production function leads to a dynamic demand amplification channel. Under a CSC production structure, the initial increase in high-skilled employment induced by the monetary expansion makes complementary capital more productive, encouraging a further rise in investment demand and creating a multiplier loop that favors high-skilled workers due to the more skill-intensive production structure. Asymmetric SAM frictions further enhance the relative demand of high-skilled workers, leading to considerably higher inequality. These findings are not qualitatively specific to monetary policy shocks but turn out to be similar for any other type of shocks that increase aggregate demand, although to a lesser extent. This is because unexpected

\footnotetext{
${ }^{17}$ In the Online Appendix we show that the ranking of different Taylor rules, with or without an explicit reaction to output stabilization depends on the presence of CSC in the face of cost-push shocks. An explicit output reaction can moderate the CSC dynamic demand amplification mechanism, mitigating the rise in the skill premium. With a standard production function, there is no such amplification to mitigate, and an explicit output reaction worsens the trade-off along the Phillips curve, leading to more volatile responses to cost push shocks.
} 
cut in interest rates stimulates investment while, say, an unexpected expansionary fiscal shock crowds it out.

On the empirical front, we have shown that an expansionary monetary shock induces a significant rise in wage inequality. However, we have not tried to match model and theoretical IRFs in our analysis, the reason being that we wanted to analyze the basic intuition of our proposed mechanism through a rather simplified model that is not rich enough to enable such a match. Yet, through the reported sectoral evidence we have highlighted the relevance of CSC in delivering a rise in wage inequality after a monetary expansion. It is in those sectors characterized by high degree of CSC, such as Manufacturing and Wholesale and Retail Trade, where the skill premium and relative employment increase according to our theoretical predictions. Asymmetric SAM frictions are a realistic feature of the labor market and therefore we found it natural to include them in our analysis on the asymmetric effects of monetary shocks in the labor market.

Our findings are not to be necessarily taken as proposals that central banks should consider reacting to measures of inequality. Issues of inequality might be best dealt with by other policy areas led by elected officials. Nonetheless, it is worth being aware of the potential distributional consequences of monetary policy actions at business-cycle frequencies, even if it is not among the objectives in the mandate of central banks. That said, our main result that monetary easing increases labor income inequality should also be interpreted with caution. We were focusing only on one particular channel, namely the effect of CSC, while in reality the channels through which monetary policy affects inequality are more complex than what our model is capable of capturing. For a more complete picture and welfare analysis further analyses and different models are required. 


\section{References}

Şahin, Ayşegül, Joseph Song, Giorgio Topa, and Giovanni L. Violante. 2014. "Mismatch unemployment." American Economic Review, 104(11): 35293564 .

Amaral, Pedro. 2017. "Monetary Policy and Inequality." Federal Resreve Bank of Cleveland Economic Commentary, 2017(01).

Barnichon, Regis, and Andrew Figura. 2015. "Labor market heterogeneity and the aggregate matching function." American Economic Journal: Macroeconomics, 7(4): 222-249.

Bell, Venetia, Michael Joyce, Zhuoshi Liu, and Chris Young. 2012. "The Distributional Effects of Asset Purchases." Bank of England Quarterly Bulletin, 2012(Q3): 254-266.

Bernanke, Ben S. 2015. "Monetary Policy and Inequality." blog of Ben Bernanke, 2015(June 1).

Blanchard, Olivier, and Jordi Galí. 2007. "Real Wage Rigidities and the New Keynesian Model." Journal of Money, Credit and Banking, 39(1): 35-65.

Blanchard, Olivier, and Jordi Galí. 2010. "Labor Markets and Monetary Policy: A New Keynesian Model with Unemployment." American Economic Journal-Macroeconomics, 2(2): 1-30.

Blankenau, William F., and Steven P. Cassou. 2011. "Industry estimates of the elasticity of substitution and the rate of biased technological change between skilled and unskilled labour." Applied Economics, 43(23): 3129-3142.

Brückner, Markus, and Evi Pappa. 2012. "Fiscal expansions, unemployment, and labor force participation: Theory and evidence." International Economic Review, 53(4): 1205-1228.

Cahuc, Pierre, Fabien Postel-Vinay, and JeanMarc Robin. 2006. "Wage bargaining with on-thejob search: Theory and evidence b." Econometrica, 74(2): 323-364.

Campolmi, Alessia, and Ester Faia. 2015. "Rethinking Optimal Exchange Rate Regimes With Frictional Labor Markets." Macroeconomic Dynamics, 19(05): 1116-1147.
Campolmi, Alessia, and Stefano Gnocchi. 2016. "Labor market participation, unemployment and monetary policy." Journal of Monetary Economics, 79: $17-29$.

Castro, Rui, and Daniele Coen-Pirani. 2008. "Why have aggregate skilled hours become so cyclical since the mid-1980s?" International Economic Review, 49(1): 135-185.

Christiano, Lawrence J., Martin S. Eichenbaum, and Mathias Trabandt. 2016. "Unemployment and Business Cycles." Econometrica, 84(4): 15231569 .

Coibion, Olivier, Yuriy Gorodnichenko, Lorenz Kueng, and John Silvia. 2017. "Innocent Bystanders? Monetary Policy and Inequality in the U.S." Journal of Monetary Economics, 88(C): 70-89.

Dolado, Juan J, Gergö Motyovszki, and Evi Pappa. 2018. "Monetary Policy and Inequality Under Labor Market Frictions and Capital-Skill Complementarity." CEPR Discussion Paper Series, , (DP12734).

Dolado, Juan J, Marcel Jansen, and Juan F Jimeno. 2009. "On-the-Job Search in a Matching Model With Heterogeneous Jobs and Workers." The Economic Journal, 119(January): 200-228.

Eeckhout, Jan, and Philipp Kircher. 2018. "Assortative Matching With Large Firms." Econometrica, 86(1): 85-132.

Fallick, Bruce C., and Charles A. Fleischman. 2004. "Employer-to-Employer Flows in the U.S. Labor Market: The Complete Picture of Gross Worker Flows." Federal Reserve Board - Finance and Economics Discussion Series, , (2004-34).

Fischer, Georg. 2017. "The US Unemployment Insurance, a Federal-State Partnership: Relevance for Reflections at the European Level." IZA Policy Paper, , (129).

Foster, Lucia, John Haltiwanger, and C J Krizan. 2006. "Market Selection, reallocation, and restructuring in the U.S. retail trade sector in the 1990s." Review of Economics and Statistics, 88(4): 748-758. 
Gornemann, Nils, Keith Kuester, and Makoto Nakajima. 2012. "Monetary Policy with Heterogeneous Agents." Federal Reserve Bank of Philadelphia Working Papers, 12(21): 1-48.

Gornemann, Nils, Keith Kuester, and Makoto Nakajima. 2016. "Doves for the Rich, Hawks for the Poor? Distributional Consequences of Monetary Policy." Board of Governors of the Federal Reserve System International Finance Discussion Papers, 2016(1167): 1-40.

Heathcote, Jonathan, Fabrizio Perri, and Giovanni L. Violante. 2010. "Unequal we stand: An empirical analysis of economic inequality in the United States, 1967-2006." Review of Economic Dynamics, 13(1): 15-51.

Kaplan, Greg, Benjamin Moll, and Giovanni Violante. 2018. "Monetary Policy According to HANK." American Economic Review, 108(3): 697743.

Koczan, Zsoka, Weicheng Lian, and Jihad Dagher. 2017. "Understanding the downward trend in labor income shares." IMF World Economic Outlook, 2017(April): 121-172.

Krusell, Per, Lee E. Ohanian, José-Víctor RíosRull, and Giovanni L. Violante. 2000. "CapitalSkill Complementarity and Inequality: A Macroeconomics Analysis." Econometrica, 68(5): 1029-1053.

Lindquist, Matthew J. 2004. "Capital-Skill Complementarity and Inequality Over the Business Cycle." Review of Economic Dynamics, 7: 519-540.

Luetticke, Ralph. 2017. "Transmission of Monetary Policy with Heterogeneity in Household Portfolios." University College London, mimeo, 1-40.

Mertens, Karel, and Morten O Ravn. 2012. "The Dynamic Effects of Personal and Corporate Income Tax Changes in the United States." American Economic Review, 103(4): 1212-1247.

Miranda-Agrippino, Silvia. 2016. "Unsurprising shocks: information, premia, and the monetary transmission." Bank of England Staff Working Paper, , (626).

Pappa, Evi, Rana Sajedi, and Eugenia Vella. 2015. "Fiscal consolidation with tax evasion and corruption." Journal of International Economics, 96(S1): S56-S75.

Ramey, Valerie A. 2016. "Macroeconomic shocks and their propagation." NBER Working Paper, w21978.

Ravenna, Federico, and Carl E Walsh. 2011. "Welfare-Based Optimal Monetary Policy with Unemployment and Sticky Prices: A Linear-Quadratic Framework." American Economie Journal: Macroeconomics, 3(2): 130-162.

Ravn, Morten O. 2006. "The Consumption-Tightness Puzzle." NBER Working Paper Series, w12421.

Ravn, Morten O, and Vincent Sterk. 2018. "Macroeconomic Fluctuations with HANK \& SAM: an Analytical Approach." manuscript, UCL.

Romer, Christina, and David Romer. 1998. "Monetary policy and the well-being of the poor." NBER Working Paper Series, , (w6793).

Romer, Christina D, and David H Romer. 2004. "A New Measure of Monetary Shocks: Derivation and Implications." American Economic Review, 94(4): 1055-1084.

Rose, Stephen J. 2017. "How Many Workers with a Bachelor's Degree Are Overqualified for Their Jobs?" Urban Institute Research Report, , (February).

Stock, James H., and Mark W. Watson. 2018. "Identification and Estimation of Dynamic Causal Effects in Macroeconomics Using External Instruments." Economic Journal, 128(610): 917-948.

Wieland, Johannes F. 2016. "Financial Dampening." NBER Working Paper Series, , (w22141).

Wolcott, Erin L. 2018. "Employment Inequality: Why Do the Low-Skilled Work Less Now?" Middlebury College mimeo. 


\section{A Labor market data}

The data for the wage premium and the relative employment ratios come from the NBER extracts of the Current Population Survey (CPS) Merged Outgoing Rotation Groups. We include in the sample only individuals in working age 15-64 and exclude part-time workers, self-employed and military employees. CPS provides monthly information from 1979:1 until 2016:6 on the participants' employment status, level of education, weekly earnings, and weekly hours of work. We classify workers as high-skilled and low-skilled according to whether they have experienced college or not. Low-skilled workers are defined as all those employed with a lower educational attainment. Defining high-skilled workers as those with college education using the NBER harmonization of education in CPS over time leads to difficulties in recovering skilled and unskilled workers at the sectoral level. To avoid inconsistencies in the definition of skilled and unskilled workers at the aggregate and at the sectoral level, we have opted to split workers depending on whether or not they have experienced some college.

\section{A.1 Harmonization}

Various variables in the Current Population Survey (CPS) are replaced over time to improve the survey instruments and adjust to changes of the labor market. In this section we illustrate how each relevant variable of this dataset was harmonized for our purposes.

Employment status. As it is commonly done when dealing with the CPS, three different variables are needed to construct an harmonized variable to distinguish employed, unemployed, and out of the labor force individuals. The harmonization is conducted as illustrated in the table below.

\begin{tabular}{lcccc}
\hline \multicolumn{1}{c}{ Harmonized variable } & & \multicolumn{3}{c}{ Original variables } \\
\cline { 1 - 2 } \cline { 5 - 5 } Education & & ftpt79 & lfsr89 & lfsr94 \\
from 1979 to 2016 & from 1979 to 1988 & from 1989 to 1993 & from 1994 to 2016 \\
\hline Out of the Labor Force & 0 & 5,7 & 5,7 \\
Employed & $1,2,4$ & 1,2 & 1,2 \\
Unemployed & 3,5 & 3,4 & 3,4 \\
\hline
\end{tabular}

Education. The variable that captures the number of years in education is revised in 1992 to capture the different type of degrees workers may undertake. We conduct the standard harmonization in the literature that is presented below and only maintain two categories of workers with respect to education: those that have never experienced college (No college education), and the rest.

Industry. We focus our attention on six industries: (1) Manufacturing, (2) Education and Health Services, (3) Agriculture, Mining and Transportation, (4) Wholesale and Retail Trade, 


\begin{tabular}{lcccc}
\hline \multicolumn{1}{c}{ Harmonized variable } & & \multicolumn{2}{c}{ Original variables } \\
\cline { 1 - 1 } Education & & gradeat & grade92 \\
from 1979 to 2016 & & fr79 to 1991 & from 1992 to 2016 \\
\hline No college education & & $<13$ & $<40$ \\
At least some college education & & $\geq 13$ & $\geq 40$ \\
\hline
\end{tabular}

(5) Professional Services, (6) Financial and Informational Services. These industries capture relatively broad categories that all together represent about 80 percent of the labor force. We generate the industry group variable aggregating workers' industry sectors as recorded by the variable dind before 2000, and dind02 from the year 2000. The table below describes the extract grouping.

\begin{tabular}{|c|c|c|}
\hline Harmonized variable & \multicolumn{2}{|c|}{ Original variables } \\
\hline Industry & dind & dind02 \\
\hline from 1979 to 2016 & from 1979 to 1999 & from 2000 to 2016 \\
\hline (i) Manufacturing & $5-20$ & $5-23,25-28$ \\
\hline (ii) Education and Health Services & $41-44$ & $40-43$ \\
\hline (iii) Agriculture, Mining and Transportation & $1-3,29,46$ & $1-3,23$ \\
\hline (iv) Wholesale and Retail Trade & $32-33$ & $21-22,46$ \\
\hline (v) Professional Services & 45 & 36-39 \\
\hline (vi) Financial and Informational Services & $24,30,34-37$ & $25-35,50$ \\
\hline
\end{tabular}

\section{A.2 Series}

We construct four types of series by aggregating nationally representative individual information from the repeated cross section of the CPS. The weighted averages for each skill group are calculated using the proper weights ERNWGT. These weights are computed each month such that, when applied, the resulting counts are representative of the national counts. Thus, this application of weights enables the results to be representative of the US population as a whole, instead of just the participants in the survey.

Employment Rate. This series is obtained as the share of employed workers in the labor force. We construct these series for any industry. We also construct these series both for any level of education and separately for each of our two levels of education. We use the employment rates for skilled workers in our VAR exercise.

Employment Ratios. This series is obtained as the ratio between employed skilled workers and employed unskilled workers. We construct these series both in the aggregate and for each industry separately. 
Hourly Wage. This series is obtained by dividing weekly earnings (earnwke) by the number of hours per week that workers report to be usually working (uhourse). We construct these series both for any industry and for each industry separately. We also construct these series both for any level of education and separately for each of our two levels of education. The skill premium is obtained as the ratio of the two hourly wages. We construct these series both for any industry and for each industry separately.

\section{A.3 Imputations}

The hourly wage series that we construct at the industry level present some outlier observations. We drop these observations and replace them with in-sample predictions that we obtain using a Kalman filter. The table below lists all outlier observations that were replaced using this procedure.

\begin{tabular}{lcc}
\hline \multicolumn{1}{c}{ Series } & & Observations replaced with imputations \\
\cline { 1 - 1 } Hourly wage, some college, industry (i) & $2016 \mathrm{M} 10$ \\
Hourly wage, no college, industry (i) & $2007 \mathrm{M} 02$ \\
Hourly wage, some college, industry (ii) & $2007 \mathrm{M} 11$ \\
Hourly wage, no college, industry (ii) & 2007M4,2007M5, 2016M10 \\
Hourly wage, some college, industry (iii) & 2005M10, 2009M1, 2009M3 \\
Hourly wage, no college, industry (iii) & 2010M6, 2011M11, 2012M9, 2016M4 \\
Hourly wage, no college, industry (iv) & 1993M12, 2005M8, 2008M1, 2015M9 \\
Hourly wage, some college, industry (v) & $2008 \mathrm{M} 10$ \\
Hourly wage, no college, industry (v) & 1993M7, 1995M1, 1997M9, 2014M6, 2016M10 \\
Hourly wage, some college, industry (vi) & $2012 \mathrm{M} 12$ \\
Hourly wage, no college, industry (vi) & $1992 \mathrm{M} 8$ \\
\hline
\end{tabular}




\section{B Empirical IRFs at the Sectoral Level}
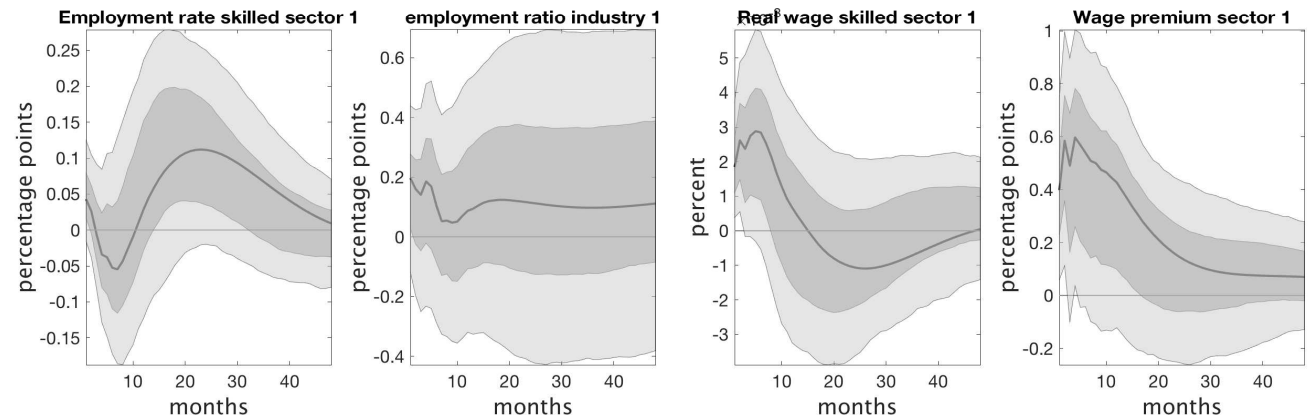

(a) Manufacturing
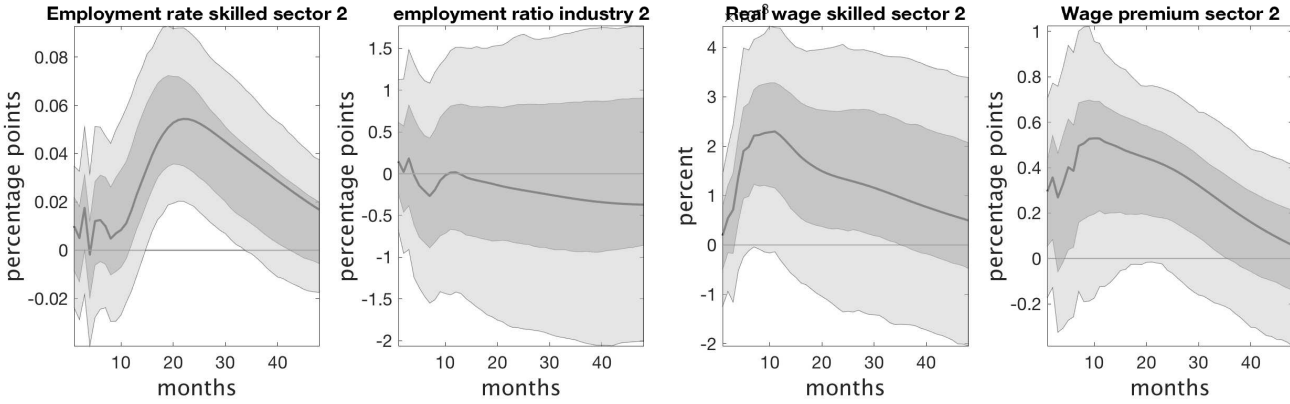

(b) Education and Health Services
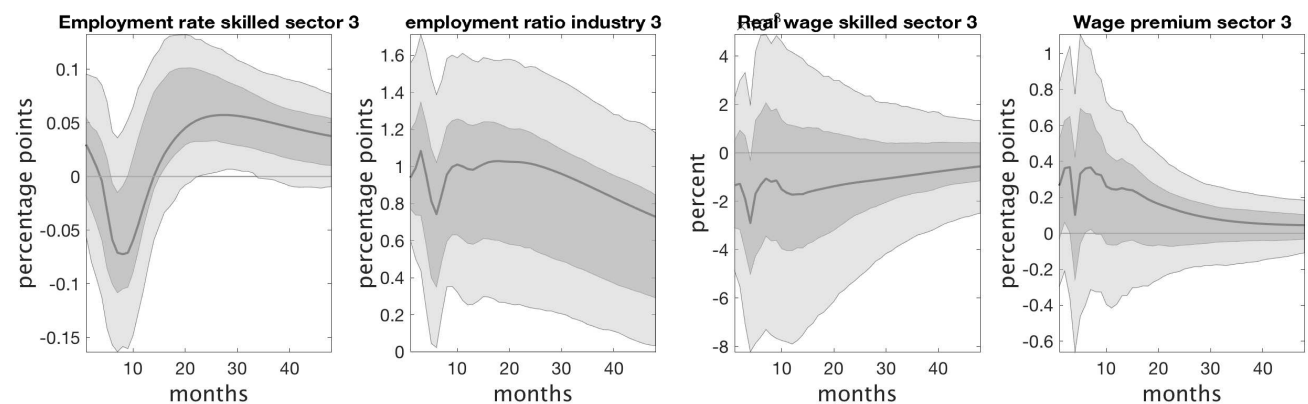

(c) Agriculture, Mining and Transportation

Figure 9: IRFs of employment ratio and skill premium in different sectors to a one percentage point unexpected reduction in the FF interest rate 

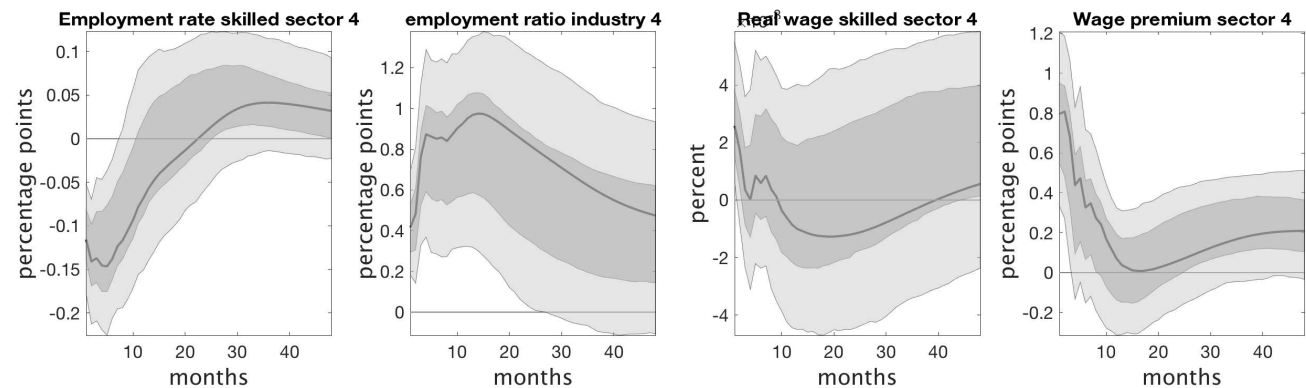

(d) Wholesale and Retail Trade
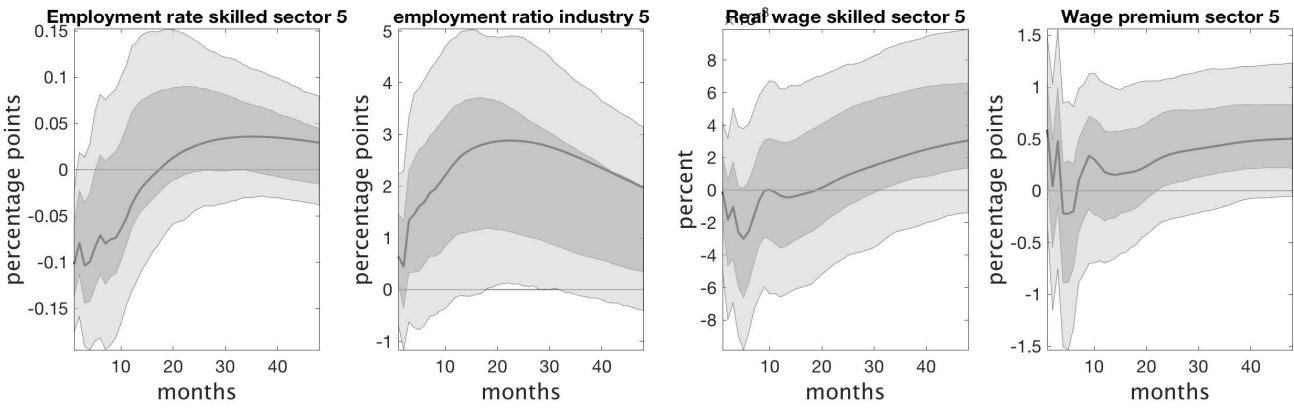

(e) Professional Services
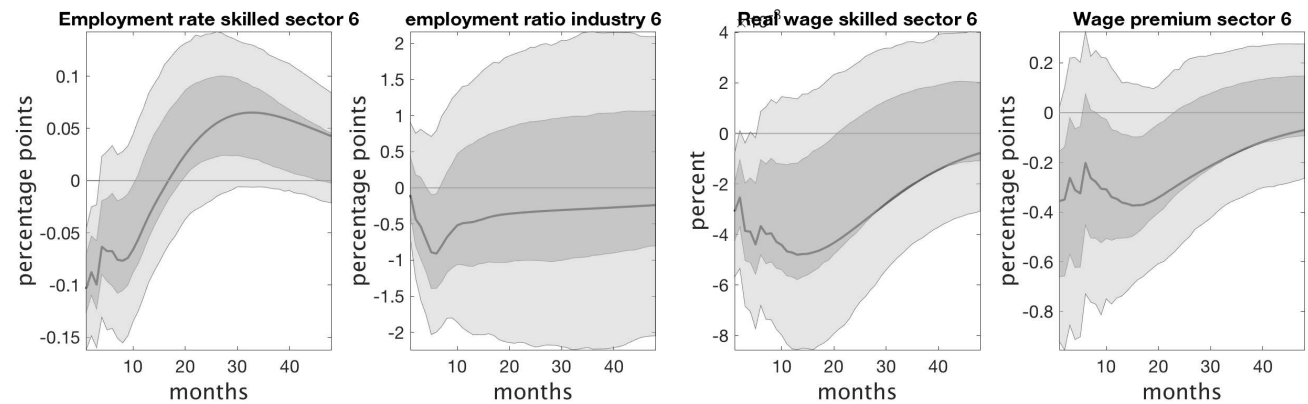

(f) Financial and Informational Services

Figure 9: IRFs of relative employment and skill premium in different sectors to a one percentage point unexpected reduction in the $\mathrm{FF}$ interest rate 


\section{Theoretical IRFs to different shocks}

\section{C.1 Expansionary government spending shock}
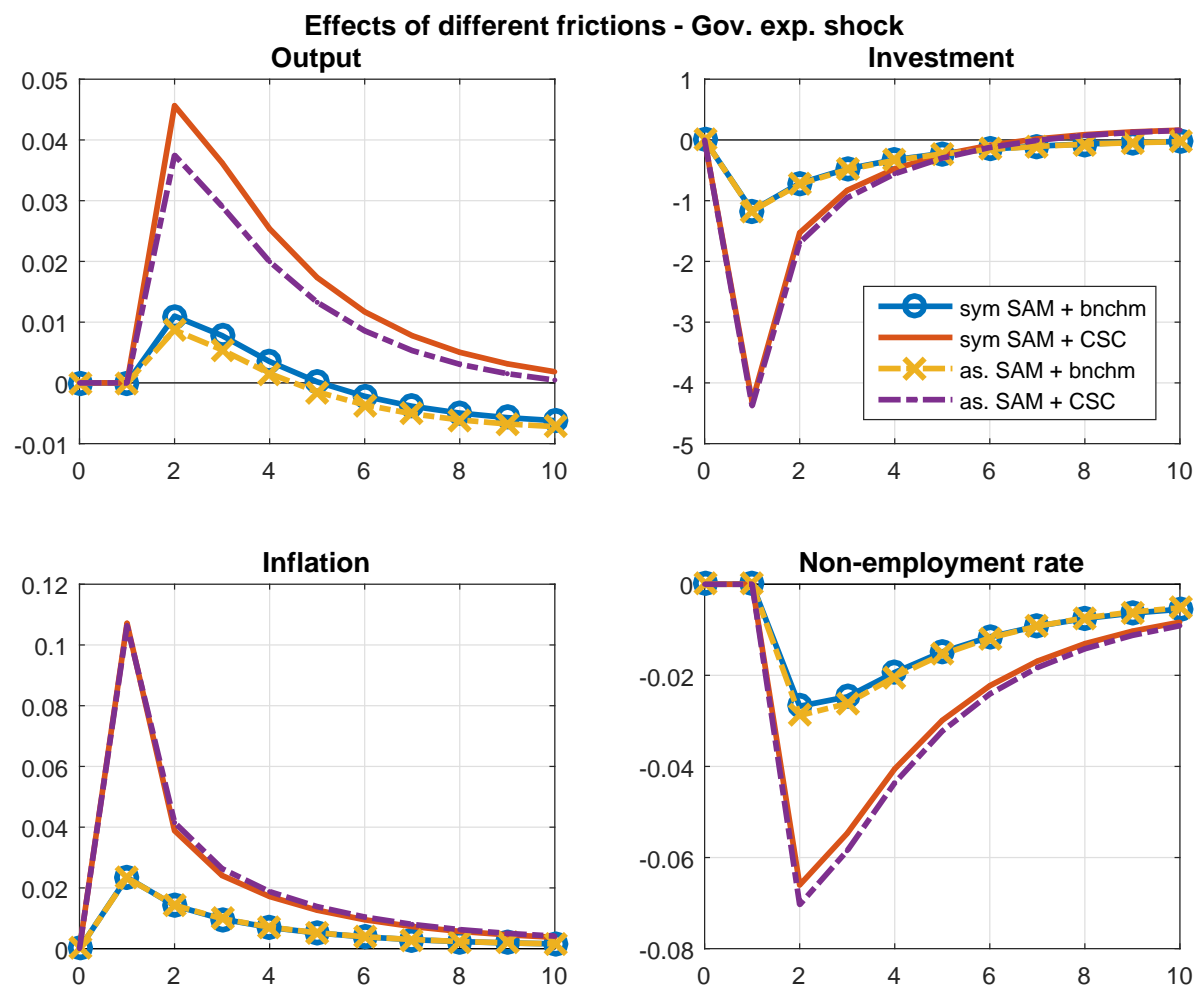

Figure 10: IRFs after a $1 \%$ increase in $G_{t}$
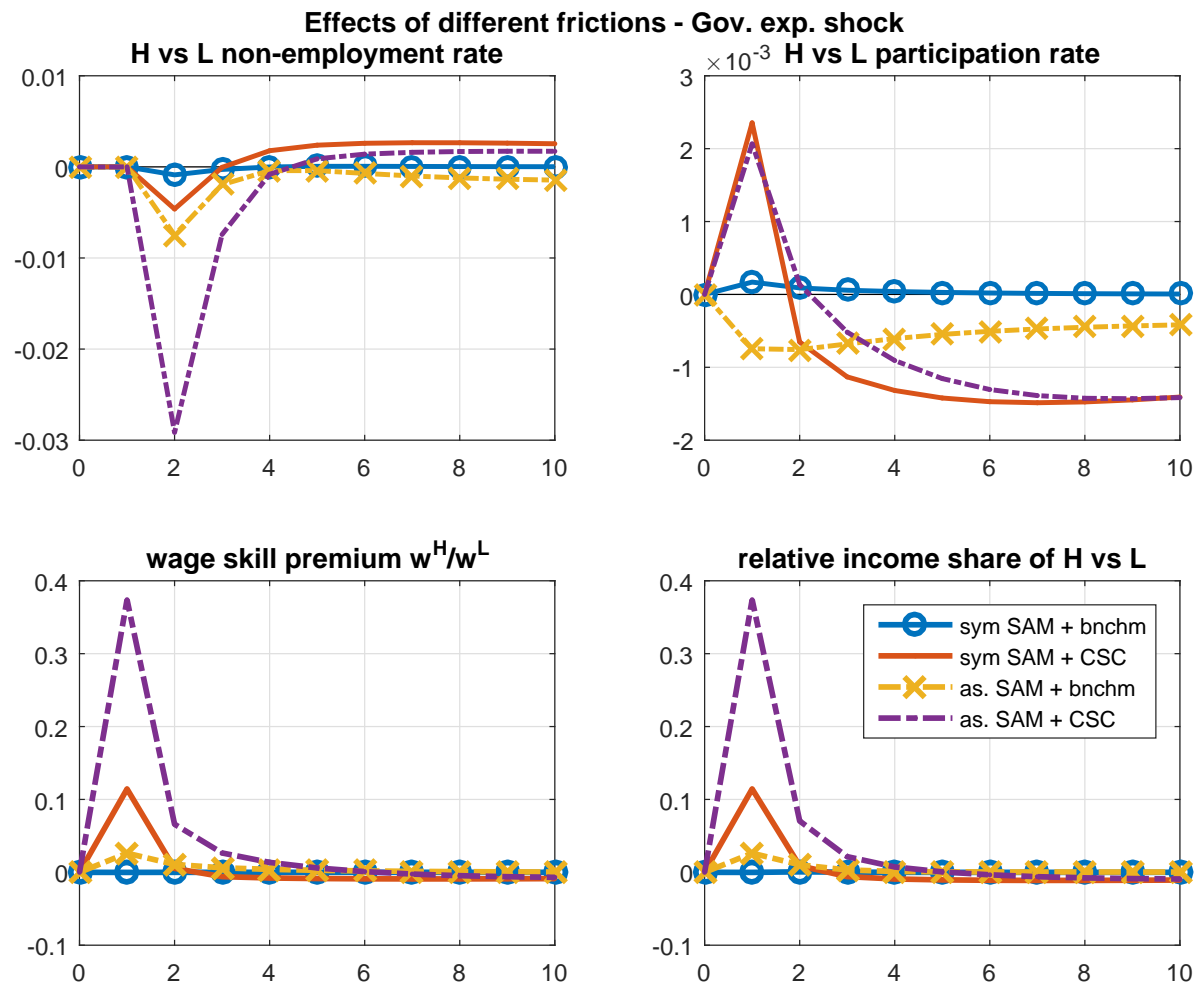

Figure 11: IRFs after a $1 \%$ increase in $G_{t}$ 
C.2 Favorable (negative) cost-push shock
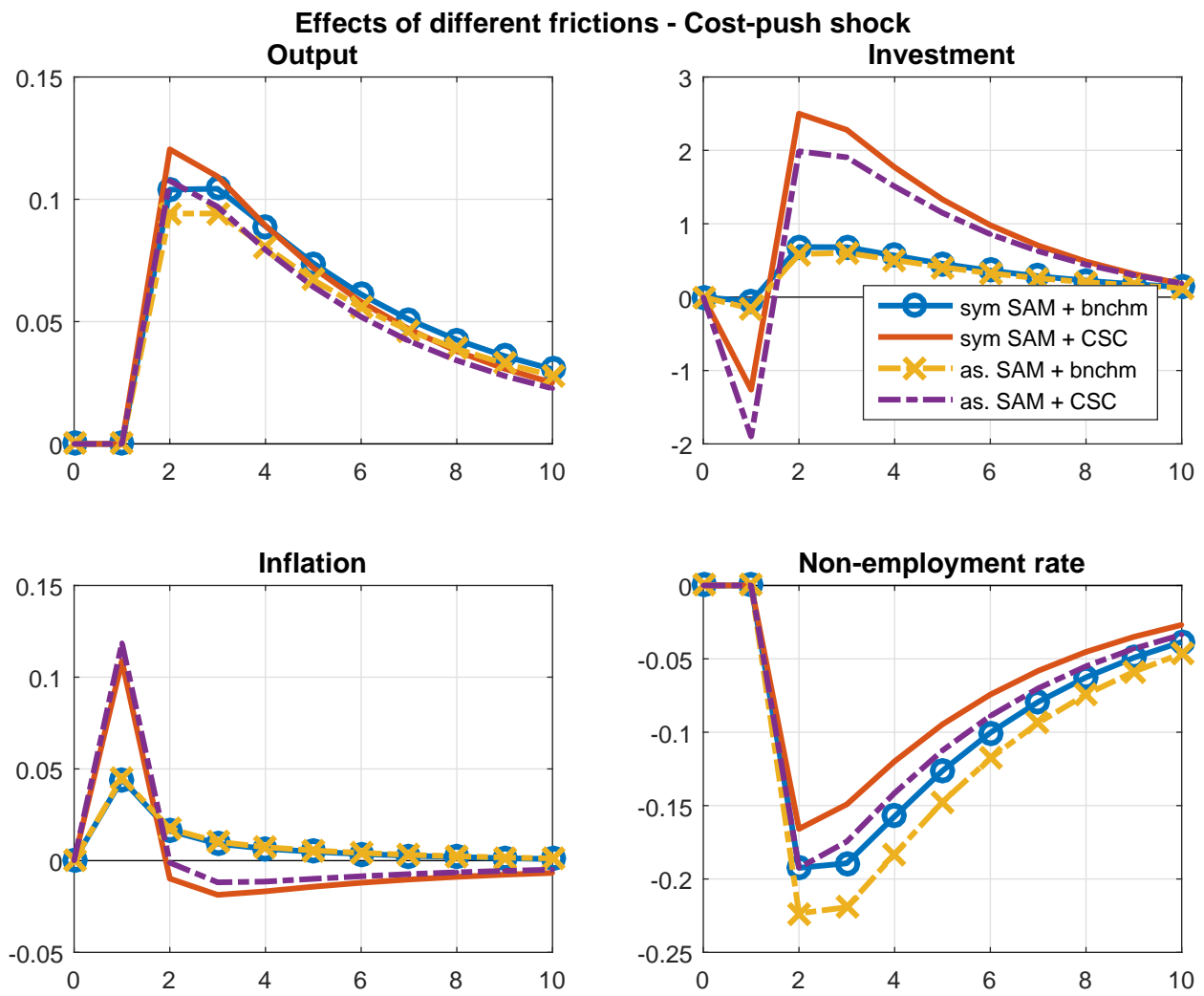

Figure 12: IRFs after a $1 \%$ decrease in $\Xi_{t}$
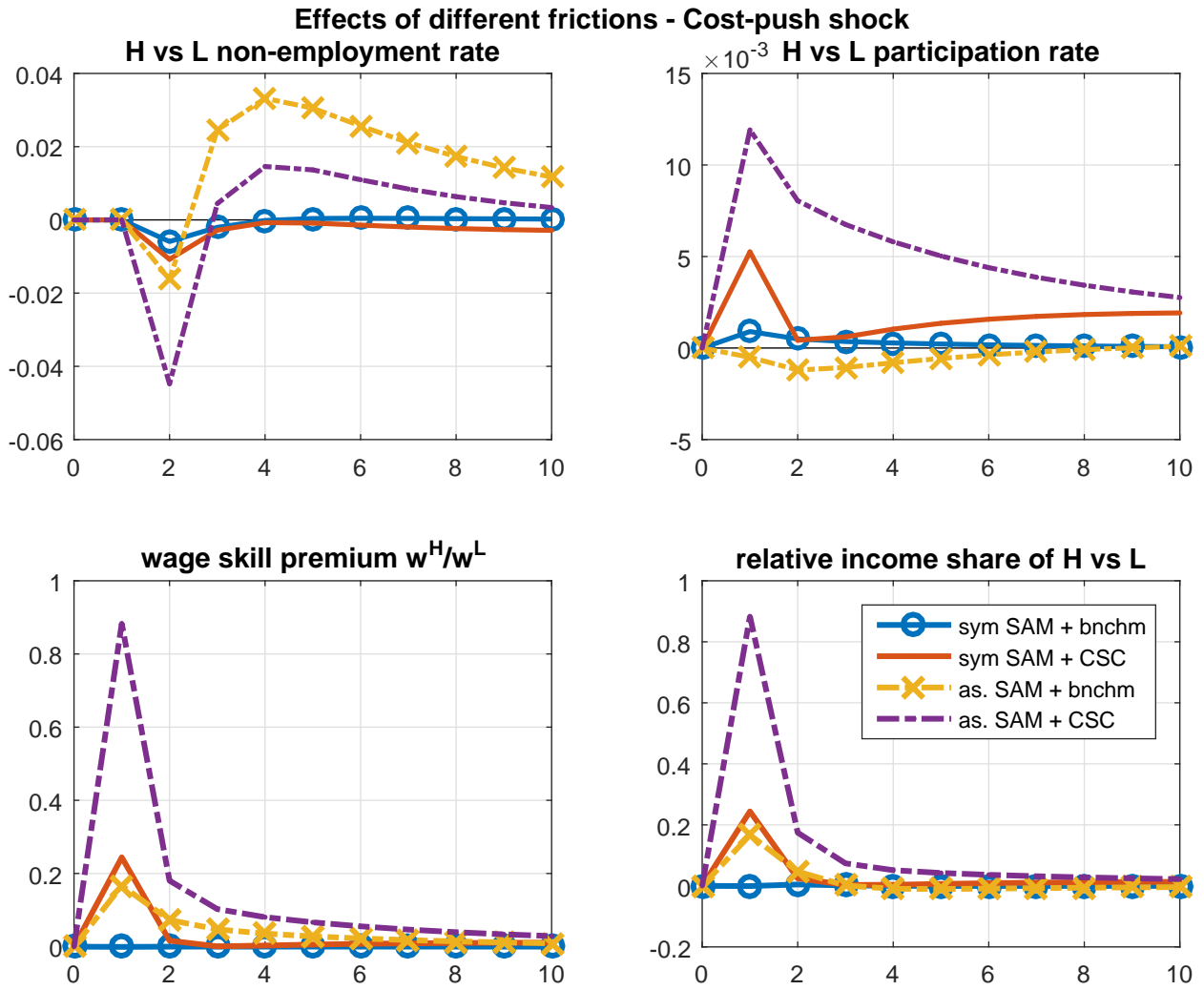

Figure 13: IRFs after a $1 \%$ decrease in $\Xi_{t}$ 


\section{C.3 Alternative steady state targets (monetary shock)}
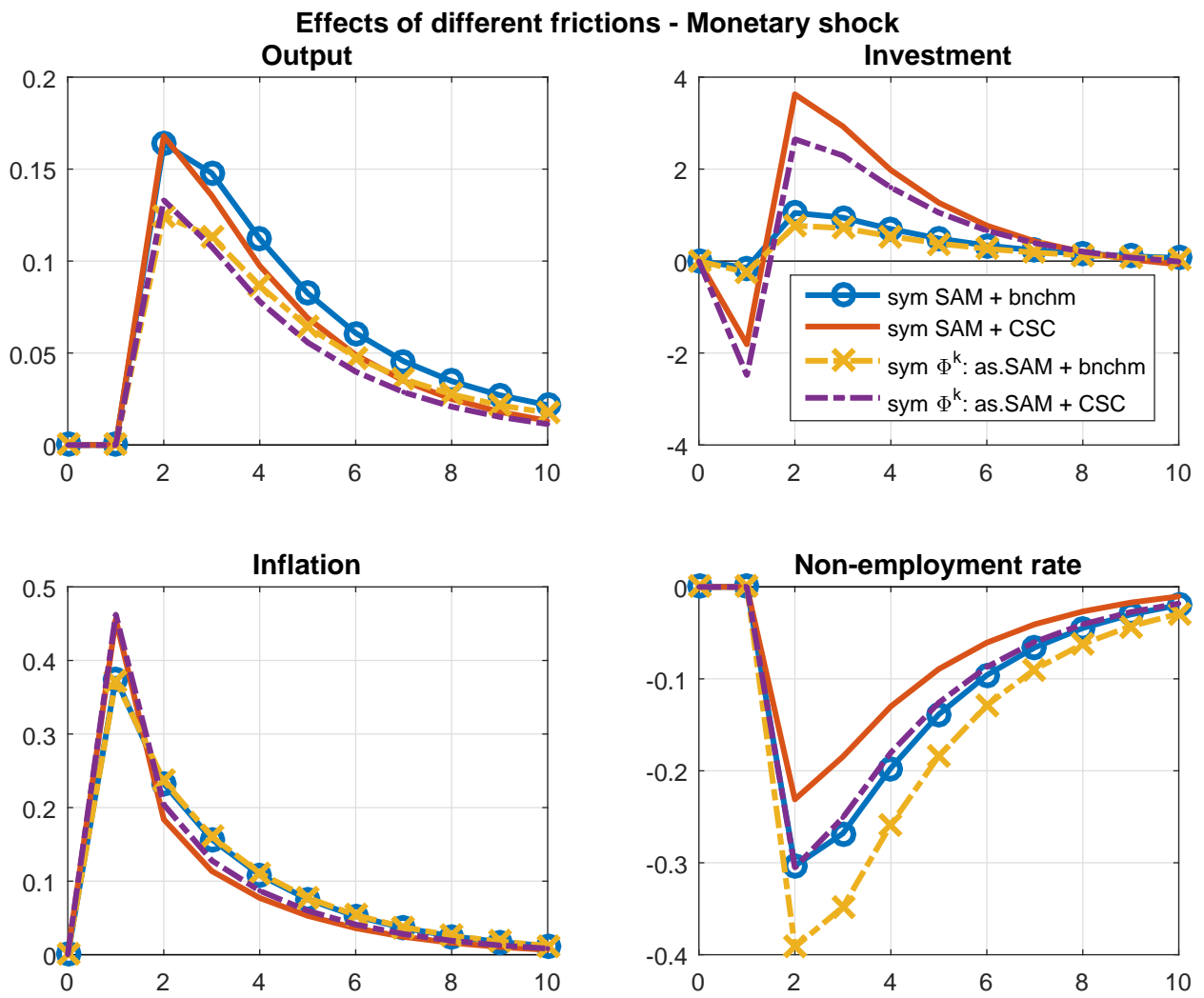

Figure 14: IRFs after a $100 \mathrm{bp}$ (annualized) cut in the policy rate
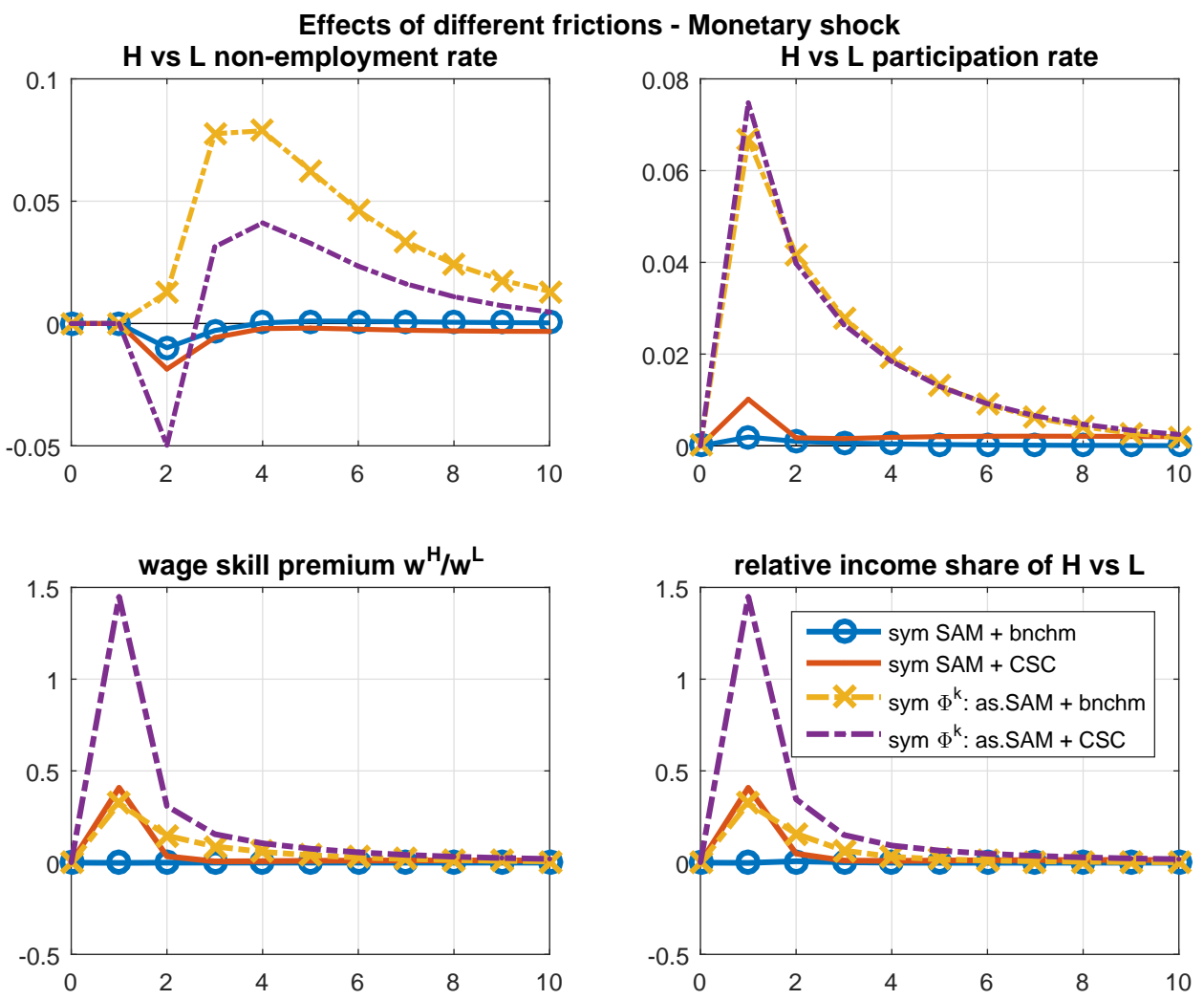

Figure 15: IRFs after a $100 \mathrm{bp}$ (annualized) cut in the policy rate 

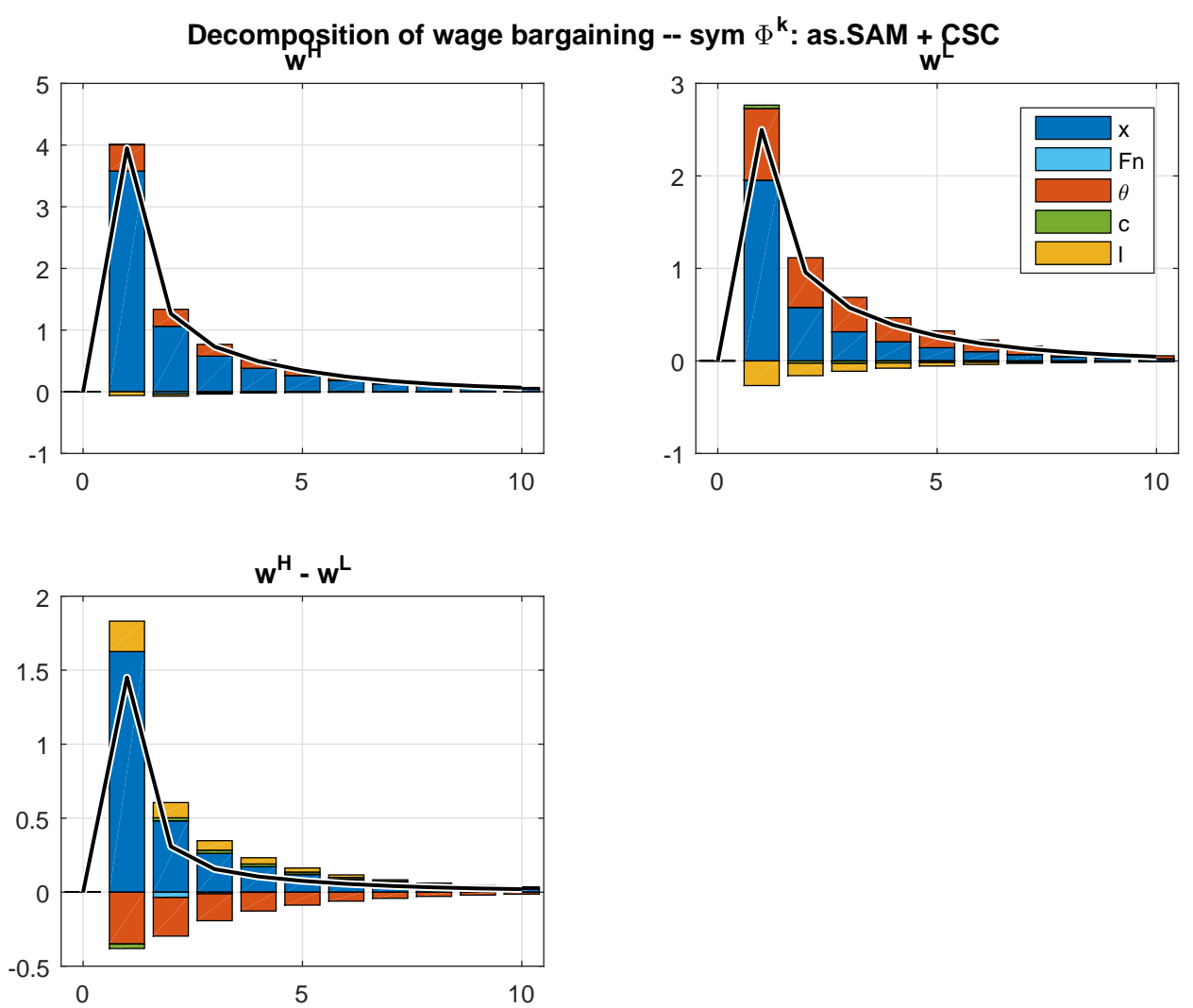

Figure 16: Decomposing real wage $\widehat{w}_{t}^{k}$ and wage premium $\widehat{w}_{t}^{H}-\widehat{w}_{t}^{L}$ dynamics, for alternative steady state targets.
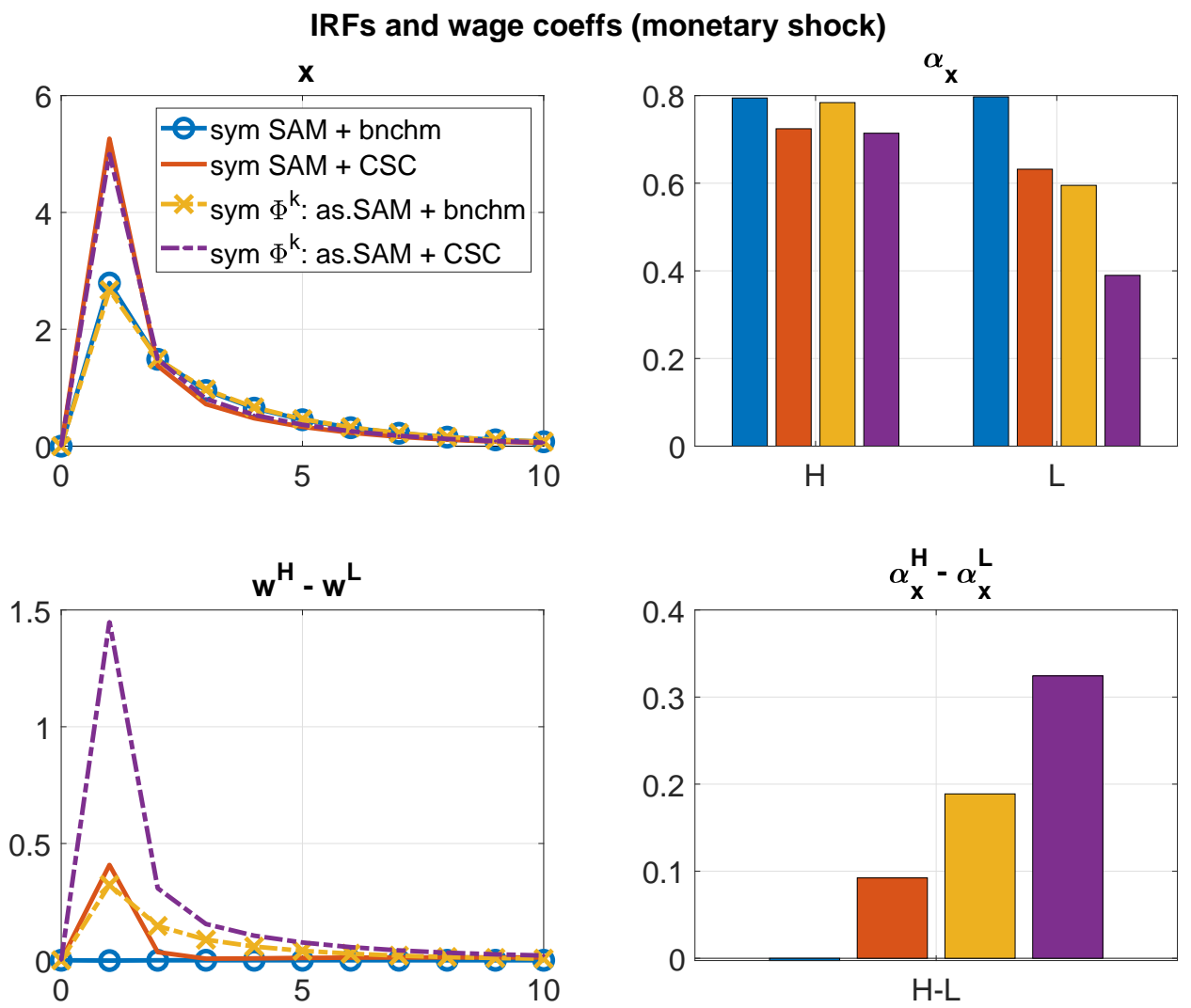

$\mathrm{H}-\mathrm{L}$

Figure 17: Comparing $\alpha_{x}^{k}$ and $\left(\alpha_{x}^{H}-\alpha_{x}^{L}\right)$, and $\widehat{x}_{t}$ and $\widehat{w}_{t}^{H}-\widehat{w}_{t}^{L}$ dynamics across different scenarios. 
In order to check the robustness of our results to asymmetry in the baseline calibration of the labor preference parameter $\Phi^{k}$, we have conducted this exercise with symmetric $\Phi^{k}$ which shows that, apart from slight quantitative differences, our main qualitative conclusions are unaffected. Asymmetry in the baseline calibration of $\Phi^{k}$ is not driving our dynamic results, and is only necessary to match skill-specific participation rate targets in the steady state.

The alternative calibration presented here differs from the baseline calibration in achieving $\Phi^{H}=\Phi^{L}=0.05$ by setting the steady state target for low-skilled participation rate at partic ${ }^{L}=$ $74.9 \%$ (instead of $66 \%$ in the baseline), which also results in a steady state wage premium of $w^{H} / w^{L}=1.6639$ (instead of 1.5306 in the baseline).

Comparing the above four figures to Figures 2, 4, 5, and 6 in the main text, it can be seen that our main conclusions are unchanged. 